\title{
La vegetación de Calakmul, Campeche, México: Clasificación, DESCRIPCIÓN Y DISTRIBUCIÓN
}

\author{
Esteban Martínez ${ }^{1}$ y Carlos G alindo-Leal ${ }^{2}$ \\ ${ }^{1} \mathrm{H}$ erbario Nacional de México (M EXU), Instituto de Biología, U niversidad Nacional Autónoma de México, \\ A.P. 70-233, Cd. Universitaria, C.P. 04510, México, D.F., \\ tel (55) 5622-5695, ext. 247 ó 323; fax 5550-1760. \\ ${ }^{2}$ World Wildlife Fund M exico, Av. México No. 51, Col. Hipódromo, M éxico 06100, D.F., M éxico. \\ tel. (52-55) 5286-5631; fax: (52-55) 5286-5637, correo electrónico: cgalindo@wwfmex.org
}

\begin{abstract}
Resumen: La región de Calakmul, en el centro de la península de Yucatán, es de gran importancia por contener el área forestal más extensa del trópico mexicano. El objetivo de este trabajo es presentar la clasificación, descripción y distribución espacial de las comunidades vegetales de la región de Calakmul. A pesar del escaso relieve topográfico de la región, la vegetación presenta una elevada heterogeneidad espacial. Las cinco asociaciones que destacan por su relevancia regional, nacional y mundial son la selva de guayacán (Guaiacum sanctum), la selva de jobillo (Astronium graveolens), la selva baja caducifolia, la selva alta y el bajo mixto. Se discuten las principales influencias sobre la vegetación de la región, incluyendo los gradientes de precipitación, el desarrollo del suelo, los disturbios naturales y el factor antropogénico. Se subraya la la necesidad de utilizar clasificaciones de vegetación suficientemente detalladas para evaluar la representatividad y la efectividad de las áreas naturales protegidas.

Palabras clave: asociaciones vegetales, tipos de vegetación, selva alta subperennifolia.

Abstract: The Calakmul region, at the center of the Yucatan peninsula, contains the largest forested area of the Mexican tropics. Our objective is to provide the classification, description and spatial distribution of the plant communities of Calakmul region. In spite of the relatively lack of topographic features there is large spatial heterogeneity in the vegetation. Five plant associations are underlined because of their regional, national and world relevance: guayacán forest (Guaiacum sanctum), jobillo forest (Astronium graveolens), low deciduous forest, tall forest and mixed seasonally flooded forest. We discuss the main factors influencing the vegetation, including rainfall gradients, soil development, natural disturbances and anthropogenic factors. This study underscores the importance of using vegetation classification with enough detail to assess the representation and effectiveness of natural protected areas.
\end{abstract}

Key words: plant associations, vegetation types, tall subdeciduous tropical forest.

$\mathbf{L}$ a región de Calakmul, ubicada en el sureste del estado de Campeche y en el centro de la península de Yucatán (Ibarra-Manríquez et al., 2002), contiene el área forestal más extensa del trópico mexicano. Su ubicación le confiere gran importancia como enlace entre las áreas forestales del sureste de Chiapas y las áreas forestales del sur de Quintana Roo. Junto con el área contigua de El Petén al sur, Calakmul representa una de las tres mayores extensiones forestales de Mesoamérica (Galindo-Leal, 1999). Paradójicamente a su relativamente buen estado actual de conservación, la región estuvo altamente modificada por los asentamientos de la civilización Maya por más de 1000 años (Turner, 1983).

A nivel nacional, la parte sur de la porción mexicana de la península de Yucatán es considerada como bosque tropical perennifolio (Rzedowski, 1978), equivalente a la selva alta perennifolia y la selva alta o mediana subperennifolia (Miranda y Hernández-X., 1963; cuadro 1). Sin embargo, la península de Yucatán en México presenta las condiciones más secas (Aw) del clima húmedo. A nivel peninsular, la región de Calakmul ha sido descrita como selva alta subperennifolia, incluyendo variantes que van desde selva alta perennifolia hasta selva mediana subperennifolia (Miranda, 1958). También se han añadido para esta región la selva baja subperennifolia, las sabanas y la vegetación de hidrófitos (Flores y Espejel, 1994; cuadro 1). A nivel regional, la mayoría de las descripciones detalladas de la composición y la estructura de la vegetación de la península de Yucatán se han llevado a cabo en el norte y centro de la región de Calakmul (Thien et al., 1982; Rico-Gray et al., 1988; Whigham et al., 1990, 1991; White y Darwin, 1995). En la 
Cuadro 1. Tipos de vegetación, asociaciones, equivalencias de nomenclatura, especies dominantes y extensión en la región Calakmul, Campeche y sus alrededores.

\begin{tabular}{|c|c|c|c|}
\hline $\begin{array}{l}\text { Tipo de } \\
\text { vegetación }\end{array}$ & Asociación & $\begin{array}{l}\text { Especies } \\
\text { dominante }\end{array}$ & Extensión \\
\hline \multicolumn{4}{|c|}{ 1. Selvas altas y medianas subperennifolias húmedas } \\
\hline $1 a$ & de chicle & Manilkara zapota & Extensa \\
\hline $1 b$ & de ramón & Brosimum alicastrum & Extensa \\
\hline $1 c$ & de pukte' & Bucida buceras & Restringida \\
\hline $1 d$ & de bayo & $\begin{array}{l}\text { Aspidosperma cruentus } \\
\text { y A. megalocarpon }\end{array}$ & Restringida \\
\hline le & de machiche & Lonchocarpus castilloi & Rara \\
\hline
\end{tabular}

\section{Selvas medianas subcaducifolias secas}

$2 \mathrm{a}$

$2 b$

$2 \mathrm{c}$

$2 d$

$2 \mathrm{e}$

$\begin{array}{lll}\text { de guayacán } & \text { Guaiacum sanctum } & \text { Extensa } \\ \text { de xu'ul de } & \text { Lonchocarpus } & \text { Restringida } \\ \text { montaña } & \text { yucatanensis } & \\ \text { de despeinada } & \text { Beucarnea pliabilis } & \text { Restringida } \\ \text { de jobillo } & \text { Astronium graveolens } & \text { Rara } \\ \text { de ja'abin } & \text { Piscidia piscipula } & \text { Rara }\end{array}$

\section{Selvas bajas}

3a baja caducifolia Varias especies

3b de ja'abin Piscidia piscipula

3c de yaytil Gymnanthes lucida

$3 d$

\section{Bajos}

4a Mixto

$4 b$

de pukte'

Bucida buceras

Asociaciones poco representadas

\section{Palmares}

5 de coyol Acrocomia mexicana Rara

5b Corozal Obyginia cohum Rara

$5 c$

Tasistal

Acoelorraphe wrightii

Rara

\section{Sabanas}

$6 a$

$6 b$

Húmeda

Seca

Cyperus spp.

\section{Asociaciones de origen secundario}

$\begin{array}{llll}7 a & \text { de tsalam } & \text { Lysiloma latisiliqua } & \text { Extensa } \\ 7 \mathrm{~b} & \text { de chaka' } & \text { Bursera simaruba } & \text { Restringida } \\ 7 \mathrm{c} & \text { de xu'ul } & \text { Lonchocarpus xuul } & \text { Rara } \\ 7 \mathrm{~d} & \begin{array}{l}\text { Bajo de sak } \\ \text { ts'iits'il che' }\end{array} & \begin{array}{l}\text { Gymnopodium } \\ \text { floribundum }\end{array} & \text { Extensa } \\ & \begin{array}{l}\text { Bajo de } \\ \text { 7e }\end{array} & \begin{array}{l}\text { Metopium brownei } \\ \text { chechem negro }\end{array} & \text { Extensa } \\ 7 \mathrm{f} & \text { Acahual } & \text { Extensa } \\ 7 \mathrm{~g} & \text { Helechal } & \text { Pteridium aquilinum } & \text { Extensa }\end{array}$

Restringida

$\begin{array}{lll}\text { Miranda } & \text { Flores y Espejel } & \text { Schulze y } \\ (1958) & (1994) & \text { Whitacre (1999) }\end{array}$

Selva alta perennifolia Selva alta perennifolia Standard U pland y Selva alta o mediana y Selva mediana forest subperennifolia subperennifolia

Dry U pland forest M esic bajo

M esic upland forest Selvas alta o mediana Selvas mediana subdecidua subcaducifolia True swamp Abundante Restringida

\section{Selva baja decidua}

Selva baja caducifolia

Selva baja subperennifolia y perennifolia

Asociación CamerariaHaematoxylon-M etopium, Low scrub swamp Chechenal de Cameraria, Tintal

Tall scrub swamp forest - M esic bajo

Corozal

Tasistal

Cohune palm upland forest Sabal forest

Hidrofitos Carrizal, tasistal Sabana Sabana Restringida 
década pasada se efectuó la cartografía de la Reserva de la Biosfera (García, 1993, 1999; Sandler et al., 1998). Estas selvas se caracterizan por la dominancia de árboles de la familia Sapotaceae (Pennington, 1990) y un sotobosque carente de elementos distintivos de las familias Araceae y Palmae, característicos de las selvas húmedas del continente (Lundell, 1933).

A pesar de la reducida información disponible acerca de esta región, los trabajos pioneros señalan algunos de los factores que determinan el establecimiento y la dinámica de la vegetación de la península (Lundell, 1934; Miranda, 1958). En particular, las descripciones de Miranda (1958), realizadas hace 45 años durante la época de la explotación de la caoba (Swietenia macrophylla), mucho antes que los nuevos asentamientos humanos se inciaran en Calakmul, son de particular importancia ya que sintetizan las características de algunos sitios con extremo detalle.

En este trabajo se presenta la distribución espacial de las comunidades vegetales de la región de Calakmul, con una descripción fisonómica, incluyendo a las especies dominantes y subdominantes. Se discuten algunas de las características geomorfológicas que determinan la distribución de las diversas asociaciones, con ejemplos de localidades típicas y variantes.

\section{Área de estudio}

En este trabajo definimos a la región de Calakmul como el área comprendida entre los paralelos 90o20'y 89o00' W y los meridianos $19^{\circ} 15^{\prime}$ y $17^{\circ} 50^{\prime} \mathrm{N}$ (figura 1 ). Desde el punto de vista geográfico, la región de Calakmul está situada en el centro de la península de Yucatán, cuando se considera la península desde el Golfo de Honduras hasta la Laguna de Términos (Miranda, 1958; Ibarra-Manríquez et al., 2002).

Fisiográficamente, la región de Calakmul constituye una unidad caracterizada por una meseta central (meseta de ZohLaguna) localizada entre los paralelos $89^{\circ} 45^{\prime}$ y $89^{\circ} 15^{\prime} \mathrm{O}$, con una altitud promedio de entre 200 y $250 \mathrm{~m}$, que se extiende en dirección norte-sur desde el paralelo $18^{\circ} 50^{\prime} \mathrm{N}$ hasta la parte norte de El Petén (Guatemala) y parte de Belice. En esta región se encuentran las principales elevaciones de Campeche (cerro Champerico, 390 m; cerro Los Chinos, 370 m; cerro El Ramonal, $340 \mathrm{~m}$ ). En este trabajo se considera solamente la porción mexicana de la meseta.

Por su lado suroriental, la meseta desciende a través de varias fallas de orientación paralela noreste-suroeste, llegando a la cuenca baja del río Hondo, donde la altitud promedio es de $20 \mathrm{~m}$. Por su lado nororiental, el descenso es continuo hasta las planicies del Caribe, a una altitud promedio de entre 30 y $40 \mathrm{~m}$. La parte norte de la meseta se convierte en lomeríos de 80 a $100 \mathrm{~m}$ en la zona de Los Chenes, que continúa en dirección noroeste hacia Champotón, conectándose con la sierra de Ticul. En su lado occidental la meseta desciende hacia el norte y hacia el centro a través de un cambio gradual en dos niveles hasta las planicies aluviales de la cuenca media del río Champotón, con una altura promedio de entre 15 y $60 \mathrm{~m}$. En su porción sur occidental se encuentra una zona de poco declive que disminuye en altitud gradualmente en dirección del río San Pedro.

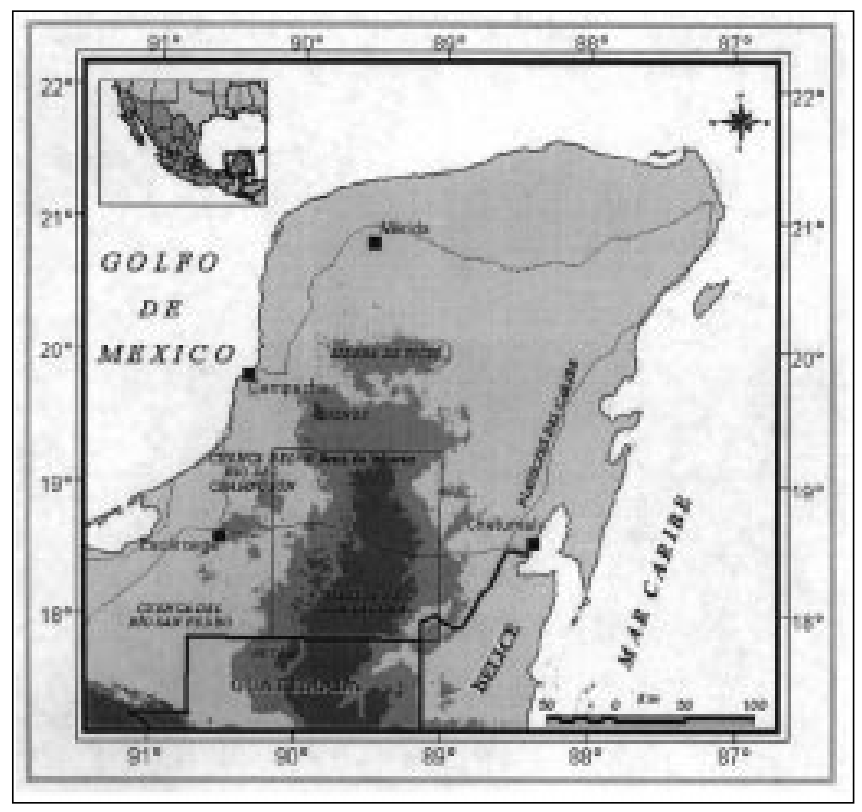

Figura 1. Localización de la región de Calakmul en el sureste del estado de Campeche, México. 
El clima de la región es tropical subhúmedo con lluvias de verano (entre junio y noviembre). La temperatura promedio anual es de $24.6^{\circ} \mathrm{C}$, y el promedio de precipitación total anual es de $1076.2 \mathrm{~mm}\left(\mathrm{Aw}_{1}\right.$ y Aw A $_{2}$ (INEGI, 1996; Comisión Nacional del Agua, 1997; figura 2). El promedio anual de precipitación es altamente variable y va de 552 a 1634 mm (INEGI, 1996). La mayor incidencia de huracanes se presenta entre agosto y septiembre. Debido a la influencia de los vientos del sureste provenientes del Caribe, se presenta un gradiente de precipitación que va del sureste, donde se presenta la máxima precipitación (aproximadamente 2000 $\mathrm{mm}$ ), al noroeste, con una precipitación de aproximadamente $500 \mathrm{~mm}$.

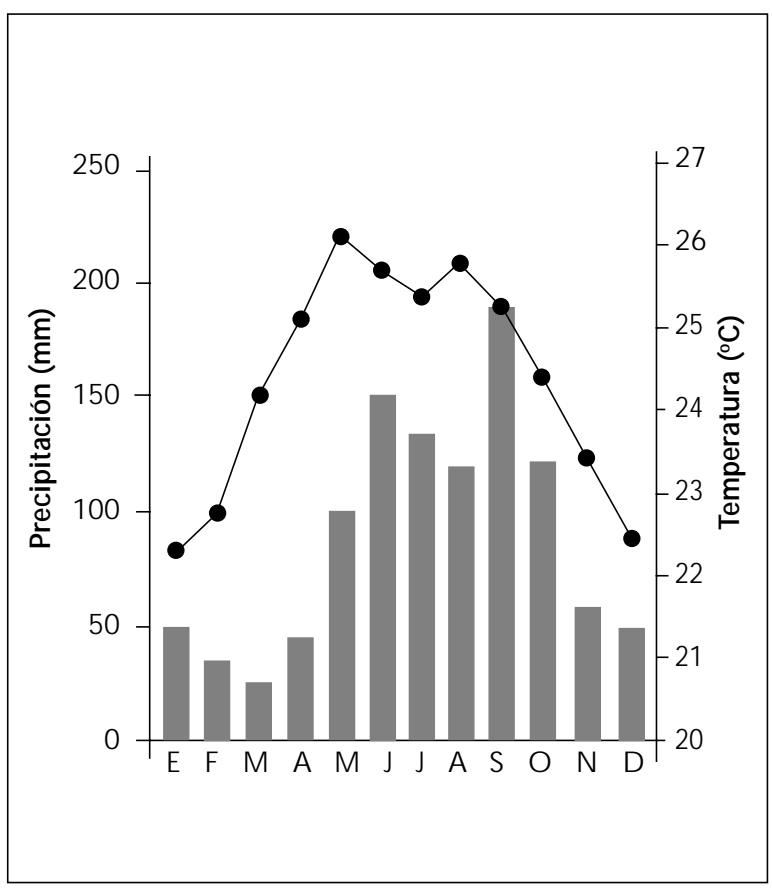

Figura 2. Patrón anual de precipitación y temperatura de la estación meteorológica Zoh Laguna, Campeche (1953-1997) (Comisión Nacional del Agua, 1997).

Gran parte del terreno de la región es de tipo cársico producido por disolución de la roca caliza. Las selvas de regiones tropicales en terrenos cársicos difieren de otras selvas por su suelo somero, menos ácido, con abundantes afloramientos de calcio (Wendt, 1993), características que reducen la disponibilidad de agua en el suelo y acentúan la sensibilidad de las plantas a las sequías estacionales.

De los 12 tipos de vegetación descritos para la península de Yucatán, en la región de Calakmul se encuentran seis (selva alta perennifolia, selva mediana subperennifolia, selva baja subperennifolia y caducifolia, sabana e hidrófitos: tular, carrizal, popal) (Flores y Espejel, 1994). Están ausentes los tipos asociados a las regiones costeras (seibadal, vegetación de dunas costeras, manglar, petén), y la franja de selvas del noroeste de la península (selva baja espinosa caducifolia y selva mediana subcaducifolia).

\section{Métodos}

Este trabajo es resultado del desarrollo de proyectos relacionados con la flora y vegetación de la región entre 1994 y 1999. Documentamos observaciones sobre la composición florística, estructura y distribución regional de las comunidades durante la recolecta de material de herbario depositado en el Herbario Nacional de México (MEXU) del Instituto de Biología, Universidad Nacional Autónoma de México. La información de distribución espacial se complementó con un modelo predictivo utilizando un análisis canónico de correspondencia (CANOCO) de las especies arbóreas dominantes en 620 puntos de descripción, la imagen de satélite Landsat TM de abril de 1995 e información ambiental (Sandler et al., 1998). Además, se llevaron a cabo 42 muestreos cuantitativos ampliamente distribuidos en la región (C. Galindo-Leal et al., datos no publicados).

Para cada asociación vegetal se presenta el nombre, la descripción, la distribución, la localidad tipo, las especies dominantes, otras especies y sus variantes. Las especies se presentan en orden de mayor a menor abundancia. Los nombres comunes fueron obtenidos de informantes locales y cotejados con Sosa et al. (1985) (apéndice 1).

\section{Resultados}

Aunque actualmente la región de Calakmul parece tener un buen estado de conservación, toda la zona estuvo fuertemenete influenciada por las actividades de los Mayas y de nuevos pobladores en los últimos dos siglos. Sin embargo, se puede distinguir entre las selvas en donde la perturbación ha sido muy selectiva (extracción de algunas especies) y etapas sucesionales recientes de entre 10 y 40 años de edad, creadas por incendios o por el abandono de milpas. Las selvas poco influenciadas se pueden agrupar jerárquicamente de acuerdo a la fisonomía y la fenología de las hojas para separar categorías ampliamente distribuidas (selvas altas y medianas húmedas, selvas medianas secas, selvas bajas y bajos) y dos más restringidas (palmares y sabanas). Dentro de los primeros cuatro tipos de vegetación se pueden distinguir 16 asociaciones principales, caracterizadas por la dominancia relativa de algunas especies. Además, se describen siete asociaciones de origen secundario (cuadro 1, figura 3 ).

\section{Selvas altas y medianas húmedas}

Las selvas altas son comunidades en donde el estrato 


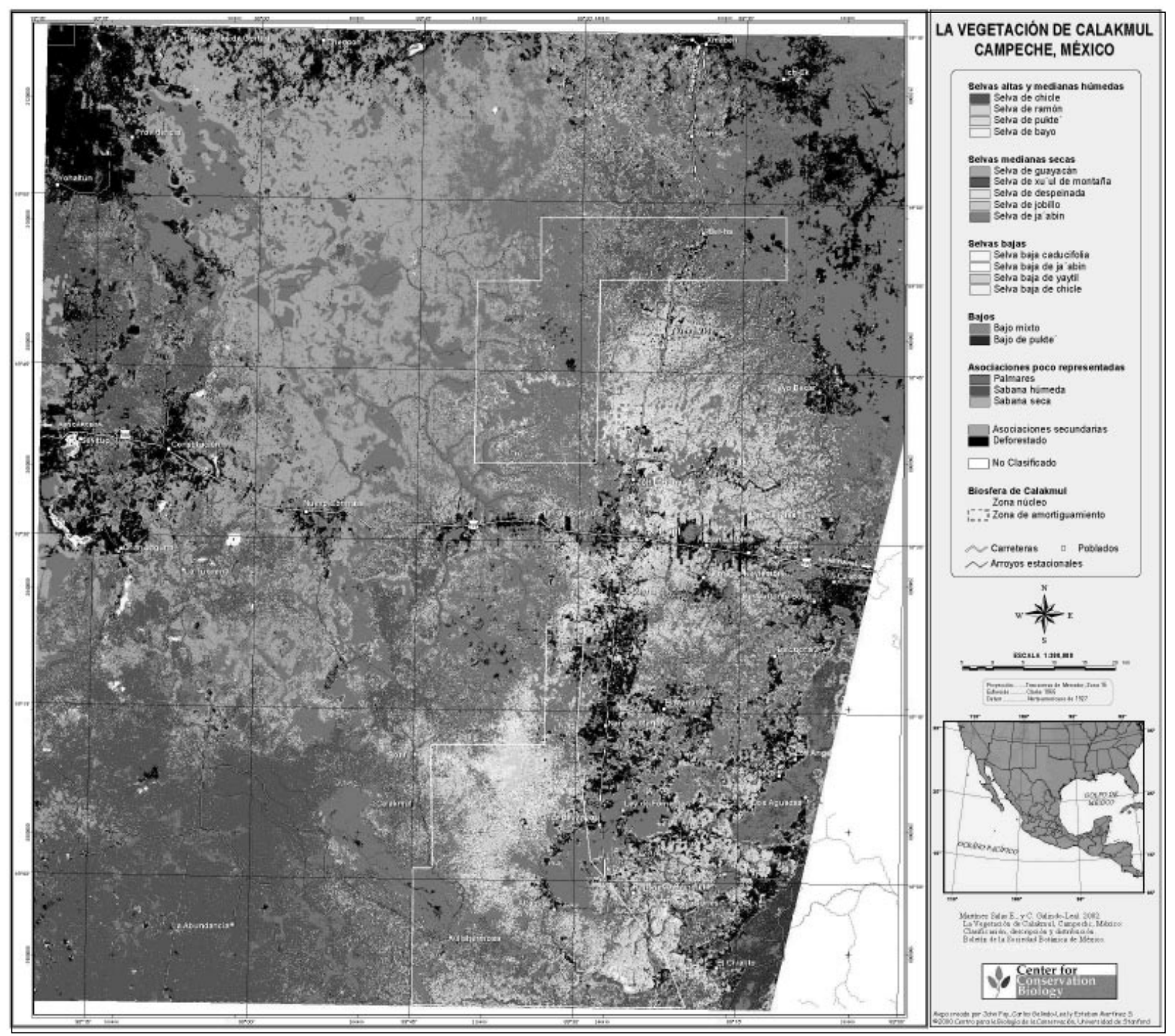

Figura 3. Mapa de comunidades vegetales potenciales.

dominante tiene 25 m o más de altura promedio. En la región se presenta en condición de subperennifolia, es decir, que entre 25 y $50 \%$ de los árboles pierden las hojas en el estío debido a las condiciones marginales de humedad. Presentan una alta diversidad de especies dominantes en relación a otras asociaciones. Los bejucos y las epífitas son escasos. Se encuentran en sitios con suelos desarrollados y protegidos de los vientos.

Estas selvas se distribuyen en la zona sur de la región, en una franja de alrededor de $30 \mathrm{~km}$ de ancho, cercana a la frontera con Guatemala. En la región suroeste se presentan intercaladas con bajos. A diferencia de otras selvas altas de México y Centroamérica, las selvas de la región carecen totalmente de palmas en el sotobosque (Astrocaryum sp.,
Bactris spp., Chamaedorea spp. y Geonoma spp.). Sólo en algunos casos se presenta de manera abundante Cryosophila argentea.

Las selvas medianas son comunidades con un estrato arbóreo dominante de entre 15 y $25 \mathrm{~m}$ de altura. Las comunidades con condición subperennifolia se han agrupado con las selvas altas, ya que son asociaciones que se presentan en condiciones ambientales similares (unidades ecológicas; Pérez y Sarukhán, 1970); además, debido a las condiciones marginales de la región (poco suelo y precipitación), las selvas altas no tienen la altura que alcanzan en otras localidades. Las selvas medianas subcaducifolias se presentan en un grupo diferente denominado "selvas medianas secas".

Las selvas medianas presentan menor número de especies 
dominantes, entre las que destacan Brosimum alicastrum, Manilkara zapota y Pouteria reticulata. Se distribuyen en las laderas orientales y en el sur en sitios con menor desarrollo de suelo, mayor influencia de los vientos y mayor exposición solar. La palma Gaussia maya es característica del sotobosque de estas selvas.

En la región se presentan por lo menos cinco asociaciones de selvas altas y medianas que se pueden identificar por una o dos especies que las dominan (cuadro 2). Las selvas de chicle (Manilkara zapota) y de ramón (Brosimum alicastrum) son las que tienen extensiones considerables. Las selvas de pukte' (Bucida buceras) y peel ma' ax o bayo (Aspidosperma cruentum y A. megalocarpon) están más restringidas. Finalmente, las selvas de machiche (Lonchocarpus castilloi) son raras.

Cuadro 2. Principales especies arbóreas de las selvas primarias (excepto palmares y sabanas) de Calakmul. Los círculos indican la especie dominante.

\begin{tabular}{|c|c|c|c|c|c|c|c|c|c|c|c|c|c|c|c|c|}
\hline Especie & $1 a$ & $1 b$ & $1 c$ & $1 d$ & le & $2 a$ & $2 b$ & $2 c$ & $2 d$ & $2 e$ & $3 a$ & $3 b$ & $3 c$ & $3 d$ & $4 a$ & $4 b$ \\
\hline Brosimum alicastrum & $x$ & 0 & $x$ & $x$ & & & & & & & & & & & & \\
\hline Manilkara chicle & 0 & $x$ & & $x$ & & & & & & & & & & & & \\
\hline Pouteria reticulata & $x$ & $X$ & $x$ & $x$ & & & & & & & & & & $x$ & & \\
\hline Pouteria sapota & $x$ & & & & & & & & & & & & & & & \\
\hline Manilkara zapota & $x$ & $\mathrm{X}$ & $\mathrm{X}$ & $\mathrm{X}$ & & & $x$ & & & & & & & 0 & $x$ & \\
\hline Swietenia macrophylla & $X$ & & $\bar{X}$ & $\bar{X}$ & & & & & & & & & & & & \\
\hline Pouteria amygdalina & $x$ & & & $x$ & & & & & & & & & & & & \\
\hline Pouteria campechiana & $x$ & & & & & & & & & & & & & $x$ & & \\
\hline Vitex gaumeri & $x$ & & & & & & & $\mathrm{X}$ & & & & & & & & \\
\hline Pimenta dioica & & $X$ & $x$ & $x$ & $x$ & & & & & & & & & & & \\
\hline Talisia olivaeformis & & $\mathrm{X}$ & & & & & & & $\mathrm{X}$ & & & & & & & \\
\hline Licaria campechiana & & $X$ & $x$ & & & & & & & & & & & & & \\
\hline Sabal mauritiiformis & & & $x$ & $\mathrm{x}$ & & & & & & & & & & & & \\
\hline Lonchocarpus castilloi & & & $x$ & & 0 & & & & & & & & & & & \\
\hline Astronium graveolens & & & $x$ & & & & & & 0 & & & & & & & \\
\hline Platymiscium yucatanum & & & $X$ & & & & & & $X$ & & & & & & & \\
\hline Bucida buceras & & & 0 & & & & & & & & & & & & $x$ & 0 \\
\hline Ficus obtusifolia & & & $x$ & & & & & & & & & & & & & \\
\hline Tabebuia rosea & & & $x$ & & & & & & & & & & & & & \\
\hline Aspidosperma cruentum & & & & 0 & & & & & & & & & & & & \\
\hline Aspidosperma megalocarpon & & & 0 & & & & & & & & & & & & & \\
\hline Calophyllum brasiliense & & & & $x$ & & & & & & & & & & & & \\
\hline Guettarda combsii & & & & $\hat{x}$ & & & & & & & & & & & & \\
\hline Protium copal & & & & $x$ & & & & & & & & & & & & \\
\hline Pseudolmedia spuria & & $X$ & & $\hat{x}$ & & & & & & & & & & & & \\
\hline Piscidia piscipula & & & & & $X$ & & & & & 0 & & 0 & & & & \\
\hline Thouinia paucidentata & & & & & & $x$ & $\mathrm{x}$ & & & & $\mathrm{x}$ & & & & & \\
\hline Guaiacum sanctum & & & & & & 0 & & $x$ & & $x$ & $\hat{x}$ & & & & & \\
\hline Beaucarnea pliabilis & & & & & & $x$ & & $\hat{0}$ & & & $\hat{x}$ & & & & & \\
\hline Esenbeckia sp. nov. & & & & & & $x$ & & & & & & & & & & \\
\hline Lysiloma latisiliqua & & & & & & & $X$ & $X$ & & & & & & & & \\
\hline Lonchocarpus yucatanensis & & & & & & & $\hat{0}$ & & $\mathrm{x}$ & & $\mathrm{x}$ & & & & & \\
\hline Haematoxylum campechianum & & & & & & & & $x$ & & & $\hat{x}$ & & & & $x$ & \\
\hline Metopium brownei & & & & & & & & $\hat{x}$ & & & & & & & $\hat{x}$ & \\
\hline Caesalpinia gaumeri & & & & & & & & $\hat{x}$ & & & & & & $x$ & & \\
\hline Bursera simaruba & & & & & & & $X$ & & $X$ & $X$ & $X$ & $X$ & $\mathrm{X}$ & $\hat{x}$ & & \\
\hline Cedrela odorata & & & & & & & & & $x$ & & & & & & & \\
\hline Krugiodendron ferreum & & & & & & & & & $\mathrm{x}$ & & & & & & & \\
\hline Caesalpinia mollis & & & & & & & & & & $X$ & & & & & & \\
\hline Exostema mexicanum & & & & & & & & & & $x$ & & & & & & \\
\hline Pseudobombax ellipticum & & & & & & & & & & & $X$ & & $X$ & & & \\
\hline Ceiba schottii & & & & & & & & & & & $x$ & & & & & \\
\hline Clusia flava & & & & & & & & & & & $x$ & & & & & \\
\hline Maytenus schippi & & & & & & & & & & & $x$ & & & & & \\
\hline Gliricidia maculata & & & & & & & & & & & & & $x$ & & & \\
\hline Gymnanthes lucida & & & & & & & & & & & & & 0 & & & \\
\hline Ateleia gummifera & & & & & & & & & & & & & & & $\mathrm{x}$ & \\
\hline Bravaisia berlandieriana & & & & & & & & & & & & & & & $x$ & \\
\hline Byrsonima bucidaefolia & & & & & & & & & & & & & & & $x$ & \\
\hline Cameraria latifolia & & & & & & & & & & & & & & & $x$ & \\
\hline
\end{tabular}




\begin{tabular}{|c|c|c|c|c|c|c|c|c|c|c|c|c|c|c|c|c|}
\hline Especie & la & $1 \mathrm{~b}$ & $1 c$ & $1 d$ & le & $2 a$ & $2 b$ & $2 c$ & $2 d$ & $2 e$ & $3 a$ & $3 b$ & $3 c$ & $3 d$ & $4 a$ & $4 b$ \\
\hline $\begin{array}{l}\text { Coccoloba cozumelensis } \\
\text { Cordia dodecandra } \\
\text { Croton icche } \\
\text { Diospyros bumelioides } \\
\text { Erytroxylum rotundifolium }\end{array}$ & & & & & & & & & & & & & & & $\begin{array}{l}x \\
x \\
x \\
x \\
x\end{array}$ & \\
\hline $\begin{array}{l}\text { Eugenia spp. } \\
\text { Eugenia winzerlingii }\end{array}$ & & & & & & & & & & & & & & & $\begin{array}{l}x \\
x \\
x\end{array}$ & \\
\hline $\begin{array}{l}\text { Lonchocarpus xuul } \\
\text { Canella winterana } \\
\text { Coccoloba acapulcensis }\end{array}$ & & & & & & & & & $x$ & & & & & $x$ & & \\
\hline $\begin{array}{l}\text { Gymnopodium floribundum } \\
\text { Spondias mombin }\end{array}$ & & & & & & & & & $\lambda$ & & & $\begin{array}{l}X \\
X\end{array}$ & & & & \\
\hline
\end{tabular}

\section{1a. Selva de chicle}

Descripción. Comunidades de amplia distribución y altura variable entre 15 y $35 \mathrm{~m}$. El chicle o sapote (Manilkara zapota) es una de las especies notables de esta comunidad por su corteza rugosa y por las marcas diagonales que deja la extracción de látex. Su época de fructificación es muy larga, abarcando de enero a mayo, y el número de frutos producida por árbol es muy alto. El chicle raramente pierde las hojas y se puede encontrar en todas las comunidades vegetales con elementos arbóreos. Generalmente son los árboles de mayores diámetros ya que la extracción del chicle evita que sean removidos.

A menudo en el sotobosque se encuentra el sapotillo (Pouteria reticulata) como especie dominante, en selvas poco alteradas. Es una selva muy diversa y con muchas especies de sapotáceas, las cuales se han adaptado a los suelos derivados de carbonatos (calizas) y sulfatos de calcio (yeso). Especies dominantes. Brosimum alicastrum, Manilkara chicle, M. zapota, Pouteria amygdalina, P. campechiana, P. reticulata, Pouteria sapota, Swietenia macrophylla y Vitex gaumeri (cuadro 2).

Variantes. En algunos lugares planos y probablemente con alteraciones muy antiguas (debido a la presencia de restos arqueológicos extensos) se localiza una asociación dominada por quina (Exostema mexicanum), de entre 20 y $25 \mathrm{~m}$ de altura. En la ladera oriental, al norte del ejido Los Ángeles, se encontraron relictos de selvas de caoba (Swietenia macrophylla) de 25 a $30 \mathrm{~m}$ de altura.

Distribución. Se encuentra en lugares planos, lomeríos, laderas ligeras y pronunciadas, con suelos de rendzinas pedregosas y litosoles. Se distribuye ampliamente en la parte sur, incluyendo las laderas orientales, occidentales y la meseta. En la parte centro-norte se distribuye en la meseta y en la ladera oriental y en las cañadas protegidas que bajan de la meseta hacia el occidente.

Localidad tipo. Entre 7 y $10 \mathrm{~km}$ al sureste del rancho Costa Maya $\left(18^{\circ} 13^{\prime} \mathrm{N}, 8^{\circ} 25^{\prime} \mathrm{O}\right.$; al este del ejido Narciso Mendoza).

\section{1b. Selva de ramón}

Descripción. Comprende comunidades de amplia distribución y con altura entre 15 y $35 \mathrm{~m}$. Brosimum alicastrum llega a tener una dominancia de más del $90 \%$, por lo que estas asociaciones se conocen como "ramonales". El ramón es una especie ampliamente utilizada y apreciada por los pobladores locales.

Variantes. En algunas cañadas muy húmedas de la ladera oriental en el centro y sur se presenta una variante de $20 \mathrm{~m}$ de altura dominada por Pseudolmedia spuria. En la parte central de la ladera occidental, en lugares con suelo poco desarrollado, en pendientes pronunciadas y generalmente asociada a ruinas, se encuentra una variante que se puede nombrar como selva baja de ramón, ya que los árboles dominantes alcanzan tan sólo entre 10 y $15 \mathrm{~m}$.

Distribución. Generalmente se encuentran en rendzinas con buen drenaje y litosoles, principalmente en las laderas orientales de la meseta. A menudo se presentan selvas de ramón sobre sitios arqueológicos y en sus alrededores. Tienen una gran variación en cuanto a su fenología foliar, ya que se pueden encontrar como selvas medianas subcaducifolias ampliamente distribuidas en las laderas suroccidentales y en mucho menor proporción en las laderas noroccidentales, hasta como selvas altas perennifolias en la meseta y las laderas orientales del centro y sur.

Localidad tipo. $5 \mathrm{~km}$ al este del poblado Nuevo Becal, camino a El Chorro (18 $\left.36^{\prime} \mathrm{N}, 89^{\circ} 15^{\prime} \mathrm{O}\right), 2 \mathrm{~km}$ al oeste del poblado 16 de Septiembre.

\section{1c. Selva de pukte'}

Descripción. Comunidades de amplia distribución que alcanzan de 20 a $40 \mathrm{~m}$ de altura, con elementos emergentes de hasta $65 \mathrm{~m}$ de altura y diámetros a la altura del pecho de hasta $3 \mathrm{~m}$. El pukte' (Bucida buceras) es una especie de origen antillano que en las Antillas generalmente crece cerca del mar, en donde los árboles son relativamente pequeños. En el este de la península de Yucatán y en El Petén se le encuentra lejos del mar y allí alcanza diámetros y alturas muy grandes. En esta asociación el pukte' se presenta en diversas 
proporciones de dominancia, desde 20 hasta $90 \%$. Especies dominantes. Brosimum alicastrum, Licaria campechiana, Manilkara zapota, Pimenta dioica, Pouteria reticulata y Talisia oliviformis. La palma Gaussia maya, aunque poco abundante, a menudo se encuentra en esta asociación (cuadro 2).

Distribución. Se encuentran a lo largo de corrientes intermitentes de agua y en lugares inundables con suelo de gley o rendzinas. Se presentan como selvas altas perennifolias en la meseta y en lugares muy protegidos y en la ladera suroccidental, y como selvas medianas subcaducifolias en la ladera oriental y a lo largo de las corrientes de agua de las laderas noroccidentales.

Especies dominantes. Astronium graveolens, Bucida buceras, Ficus obtusifolia, Lonchocarpus castilloi, Platymiscium yucatanum, Tabebuia rosea, Sabal mauritiiformis y Swietenia macrophylla (cuadro 2).

Variantes. En lugares inundables similares a los de las selvas de pukte' es posible encontrar también otras asociaciones en lugares muy particulares y áreas pequeñas como son las selvas de makulis (Tabebuia rosea) de 18 a $30 \mathrm{~m}$ de altura, de pich (Enterolobium cyclocarpum) de 20 a $30 \mathrm{~m}$ de altura y las de tinto de montaña (Haematoxylum brasiletto) de $20 \mathrm{~m}$ de altura.

Localidad tipo. $8 \mathrm{~km}$ al noreste del ejido El Manantial, al noreste de Narciso Mendoza (18 $\left.18^{\circ} \mathrm{N}, 89^{\circ} 20^{\prime} \mathrm{O}\right)$.

\section{1d. Selva de bayo}

Descripción. Comunidades de entre 25 y $40 \mathrm{~m}$ de altura, en donde son notables dos especies: el bayo rojo (Aspidosperma cruentus) y el bayo blanco (A. megalocarpon). Se pueden encontrar desde comunidades medianas subperennifolias hasta altas perennifolias.

Especies dominantes. Las dos especies (Aspidosperma cruentum y A. megalocarpon) son fáciles de reconocer por su fisonomía con troncos esbeltos, muy rectos, con ramificaciones altas, que a menudo se presentan como árboles emergentes. Aunque los bayos sobresalen en esta comunidad por su fisonomía, comparten la dominancia con varias especies. Aspidosperma cruentum se encuentra principalmente en el sur de la meseta y de la ladera oriental, mientras que A. megalocarpon es abundante en el suroeste de la meseta. Otras especies dominantes son: Brosimum alicastrum, Calophyllum brasiliense, Guettarda combsii, Manilkara zapota, Pimenta dioica, Pouteria amygdalina, $P$. reticulata, Protium copal, Pseudolmedia spuria, Sabal mauritiiformis y Swietenia macrophylla (cuadro 2).

Variantes. En la ladera suroriental, en lugares con poca pendiente y en donde el agua se acumula se encuentra una asociación dominada por Calophyllum brasiliense, con alturas de $25 \mathrm{a} 30 \mathrm{~m}$. En la misma área, pero distribuida tanto en la ladera como en la meseta, se encuentra una asociación dominada por Aspidosperma cruentum y Manilkara zapota, con alturas de entre 22 y $30 \mathrm{~m}$. En el sur de la meseta, sobre las cimas de los cerros, contigua a la selva de bayo, se distingue una asociación perennifolia dominada por Gymnanthes lucida, con una altura de entre 20 y 25 m.

Distribución. Se encuentran en suelos que varían de rendzinas bien desarrolladas, pedregosas, hasta suelos de gley. Se distribuyen en el sur de la meseta en valles inundables (medianas con $A$. cruentum) y en lomas y cañadas pronunciadas (altas con A. megalocarpon).

Localidad tipo. $3 \mathrm{~km}$ al sur de la ranchería Las Delicias $\left(18^{\circ} 32^{\prime} \mathrm{N}, 89^{\circ} 12^{\prime} \mathrm{W}\right), 12 \mathrm{~km}$ al sur del ejido Ley de Fomento.

\section{1e. Selva de machiche}

Descripción. Comunidades dominadas por machiche (Lonchocarpus castilloi) que se presentan como selvas altas subperennifolias y perennifolias, de 28 a $60 \mathrm{~m}$ de altura. Las más altas tienen al ja'abin (Piscidia piscipula) como especie codominante. Esta asociación estuvo dominada por caoba (Swetenia macrophylla), lo que se infiere por el gran número de tocones de gran tamaño ( $>2 \mathrm{~m}$ de diámetro), que aún persisten en el sitio.

Especies dominantes. La especie dominante, Lonchocarpus castilloi, ha sido altamente apreciada por tener una madera excelente para el uso local y para el mercado. En los remanentes medianamente conservados se observaron árboles de machiche de más de $60 \mathrm{~m}$ de altura, con diámetros a la altura del pecho de más de $1.5 \mathrm{~m}$, y de Piscidia piscipula de entre 30 y $50 \mathrm{~m}$ de altura, distribuidos en manchones. Es muy probable que la dominancia actual de ja' abin se deba a la apertura del bosque asociada a la extracción de caoba. Otra especie muy abundante en esta asociación es Pimenta dioica (cuadro 2).

En esta asociación se registraron por primera vez varias especies que generalmente se encuentran en sitios más húmedos que los existentes en la región, como Chrysophyllum venezuelanense, Hirtella americana y Philodendron sp. (Martínez et al., 1999).

Variantes. Las selvas de machiche de la ladera suroriental son de altura media, de 30 a $40 \mathrm{~m}$, mientras que las de la ladera suroccidental tienen una altura media de $60 \mathrm{~m}$ debido a la protección que les confiere la meseta contra los vientos del sureste.

Distribución. Se encuentran en zonas planas o laderas de pendiente ligera, con suelos pedregosos de gley y rendzinas, inundadas por un periodo corto del año. Seguramente tuvieron amplia distribución, pero en la actualidad están restringidas a lugares inaccesibles o bajo protección (en el sur de la zona núcleo de la Reserva de la Biosfera Calakmul), en la parte sur de la meseta y en la ladera suroccidental.

Localidad tipo. Frontera con Guatemala, $105 \mathrm{~km}$ sur del poblado Constitución $\left(17^{\circ} 48^{\prime} \mathrm{N}, 90^{\circ} 08^{\prime} \mathrm{O}\right)$.

\section{Selvas medianas secas}

En este grupo se encuentran las selvas de 15 a $25 \mathrm{~m}$ de altura que presentan condición subcaducifolia. Estas selvas están 
distribuidas en la ladera occidental, a lo largo de la meseta y en la planicie nororiental.

Entre las selvas medianas secas se pueden distinguir por lo menos cinco asociaciones. La selva de guayacán es la de mayor extensión. Las selvas de despeinada y xu'ul de montaña ocupan una extensión moderada, mientras que las de jobillo y ja' abin son raras (cuadro 2).

\section{2a. Selva de guayacán}

Descripción. Su altura varía entre 12 y $22 \mathrm{~m}$ en promedio. Se presenta como baja a mediana, subcaducifolia a subperennifolia. Son comunidades muy susceptibles al fuego y al saqueo de madera dado que el guayacán es una especie altamente cotizada. Las especies dominantes son el guayacán (Guaiacum sanctum) y el naranjillo (Esenbeckia sp. nov.). Especies dominantes. Las especies dominantes son Beaucarnea pliabilis, Esenbeckia sp. nov., Guaiacum sanctum y Thouinia paucidentata. Guaiacum sanctum es una especie perennifolia de hojas micrófilas, con corteza renegrida y escamosa, que llega a representar entre 20 y $60 \%$ de la dominancia. En la parte centro occidental, Esenbeckia sp. nov., fácilmente distinguible por su corteza amarillo-verdosa, similar a la de la naranja, se presenta como codominante. En las laderas noroccidentales Beaucarnea pliabilis es codominante (cuadro 2).

Variantes. En lugares con suelo más desarrollado en la ladera centro occidental se localiza una asociación dominada por Esenbeckia sp. nov., de 12 a $20 \mathrm{~m}$ de altura. En lugares con escasez de suelo y afloramientos cársicos con proceso de disolución acentuado, en la ladera noroccidental, se presenta como selva baja caducifolia. La estructura de esta variante es muy abierta.

Distribución. Comunidades distribuidas ampliamente en la laderas y planicies del centro y noroccidente. Se presentan en lomas y lugares planos con litosoles y litosoles con rendzinas. No se han registrado afloramientos yesosos en el área de distribución de esta selva.

Localidad tipo. $\mathrm{Km} 32$ de la carretera a la zona arqueológica de Calakmul (18o23` N, 89o53’ O).

\section{2b. Selva de xu'ul de montaña}

Descripción. Comunidades de entre 12 y 25 (-30) m de altura, en donde Lonchocarpus yucatanensis representa de 20 a $70 \%$ de los individuos. Se presentan como caducifolias en pendientes pronunciadas y suelo escaso, y como subperennifolias en lugares planos con una capa delgada de suelo. En estos últimos sitios pueden alcanzar hasta $30 \mathrm{~m}$ de altura.

Especies dominantes. La especie dominante es Lonchocarpus yucatanensis. Esta especie ha sido confundida frecuentemente con Lonchocarpus xuul, ya que ambas son extremadamente parecidas en sus estructuras vegetativas, por lo que se pensaba que el xu'ul de montaña era una especie muy rara. Otras especies abundantes son Bursera simaruba, Lysiloma latisiliqua, Manilkara zapota y Thouinia paucidentata. Distribución. Se encuentran a lo largo de la ladera occidental, desde el límite con Guatemala hasta la zona de Dzibalchén, en lugares con pendientes ligeras a muy pronunciadas y suelos rocosos muy someros.

Localidad tipo. Km 40 camino a la Zona Arqueológica de Calakmul (18 $\left.18^{\circ} \mathrm{N}, 8^{\circ} 48^{\prime} \mathrm{O}\right)$.

\section{2c. Selva de despeinada}

Descripción. Comunidad de 10 a $18 \mathrm{~m}$ de altura, dominada por la despeinada o ts'ipil (Beaucarnea pliabilis) que es una planta arborescente de hasta más de $2 \mathrm{~m}$ de diámetro a la altura del pecho y ramas muy pequeñas.

Especies dominantes. La despeinada (Beaucarnea pliabilis) comparte la dominancia con el guayacán (Guaiacum sanctum) en la ladera noroccidental. En la planicie nororiental comparte la dominancia con Lysiloma latisiliqua y Metopium brownei. Otras especies abundantes son Caesalpinia gaumeri, Haematoxylum campechianum y Vitex gaumeri (cuadro 2). Distribución. Se distribuye en la ladera y la planicie nororiental, y en la ladera noroccidental en lomas y laderas ligeras, con litosoles y suelos de gley inundables.

Localidad tipo. $6 \mathrm{~km}$ al norte del poblado de Bel-ha y $5 \mathrm{~km}$ al este $\left(19^{\circ} 00^{\prime} \mathrm{N}, 89^{\circ} 15^{\prime} \mathrm{O}\right)$.

\section{2d. Selva de jobillo.}

Descripción. Comunidades de 15 a $25 \mathrm{~m}$ de altura, en donde el jobillo (Astronium graveolens) llega a representar de 20 a $30 \%$ de los individuos. Varía de caducifolia a subperennifolia, dependiendo del desarrollo del suelo y de la composición de las otras especies dominantes. Conforme disminuye el grosor del suelo su commportamiento es más caducifolio.

Especies dominantes. Astronium graveolens, Bursera simaruba, Cedrela odorata, Coccoloba acapulcensis, Krugiodendron ferreum, Lonchocarpus yucatanensis, Platymiscium yucatanum y Talisia oliviformis (cuadro 2).

Distribución. Distribuida en la planicie centro-occidental en laderas ligeras y lugares planos, sobre litosoles y rendzinas pedregosas.

Localidad tipo. $1 \mathrm{~km}$ al sur de la Zona Arqueológica de Balamkú, al norte del ejido Conhuas por el camino viejo $\left(18^{\circ} 35^{\prime} \mathrm{N}, 89^{\circ} 55^{\prime} \mathrm{O}\right)$.

\section{2e. Selva de ja'abin}

Descripción. Comunidades fuertemente impactadas por la extracción de Cedrela odorata. El ja'abin (Piscidia piscipula) representa de 20 a $60 \%$ de los individuos. Alcanzan aproximadamente $18 \mathrm{~m}$ de altura y son de caducifolias a subperennifolias.

Especies dominantes. Bursera simaruba, Caesalpinia mollis, Exostema mexicanum, Guaiacum sanctum y Piscidia piscipula (cuadro 2).

Distribución. Se distribuyen en la ladera centro occidental y noroccidental en lugares planos, lomas y valles, con suelos 
de litosoles y rendzinas someras.

Localidad tipo. $44 \mathrm{~km}$ al noroeste del poblado de Conhuas, en el camino a Yohaltún. Ampliamente distribuida en los alrededores de Dzibalchén (18 $\left.50^{\circ} \mathrm{N}, 90^{\circ} 08^{\prime} \mathrm{O}\right)$.

\section{Selvas bajas secas}

Son comunidades primarias y secundarias con árboles de entre 5 y $15 \mathrm{~m}$ de altura en promedio. Se presentan como caducifolias o subcaducifolias dependiendo de la precipitación total anual. En años de sequía severa, la mayor parte de las especies pierden las hojas. Se distribuyen a lo largo de la parte occidental de la meseta y en los cerros con poco desarrollo de suelo de la ladera centro y noroccidental.

Las selvas bajas se pueden dividir en por lo menos cuatro asociaciones primarias y tres de origen secundario. La selva baja caducifolia es la de mayor extensión. La selva de ja'abin es moderadamente abundante, pero restringida al norte de la meseta. Las selvas de yaytil y chicle ocupan extensiones menores (cuadro 2).

\section{3a. Selva baja caducifolia.}

Descripción. Comunidad de menos de $15 \mathrm{~m}$ de altura en donde $75 \%$ o más de los árboles pierden las hojas en el estío por un periodo mínimo de dos meses. El elemento caducifolio puede variar en diferentes años dependiendo de la duración o la severidad de la estación seca. En años muy húmedos, no todos los árboles pierden las hojas. La mayoría de las especies pierden las hojas en los meses de febrero y marzo. Lysiloma latisiliqua genera nuevas hojas en abril, mientras que Piscidia piscipula produce frutos muy grandes, de color verde, con apariencia de hojas. Otras especies permanecen sin hojas durante cinco meses, hasta el inicio de la época de lluvias (p. ej., Bursera simaruba, Cedrela odorata, Pseudobombax ellipticum).

Especies dominantes. Dependiendo de las diversas condiciones ambientales en las que se encuentran, estas selvas están dominadas por diferentes especies como Beaucarnea pliabilis, Bursera simaruba, Ceiba schotti, Guaiacum sanctum, Haematoxylum campechianum, Lonchocarpus yucatanensis, Maytenus schippi, Pseudobombax ellipticum y Thouinia paucidentata (cuadro 2).

Variantes. Se pueden distinguir por lo menos nueve asociaciones primarias dominadas por Beaucarnea pliabilis, Bursera simaruba, Clusiaflava, Exostema mexicanum, Guaiacum sanctum, Lonchocarpus yucatanensis, Piscidia piscipula, Pseudobombax ellipticum y Thouinia paucidentata. Las dos últimas asociaciones también pueden ser secundarias. También en este grupo se encuentran tres asociaciones de origen secundario dominadas por Lonchocarpus xuul, Lysiloma latisiliqua y Metopium brownei.

Distribución. Se encuentran en gran diversidad de ambientes en toda la región, en lugares con pendientes pronunciadas y suelos poco desarrollados, principalmente a lo largo de la meseta y en las laderas noroccidentales.
Localidad tipo. $1 \mathrm{~km}$ al oeste del ejido Plan de San Luis. 1 $\mathrm{km}$ al oeste del rancho Costa Maya. $6 \mathrm{~km}$ al oeste de Ukum $\left(19^{\circ} 13^{\prime} \mathrm{N}, 89^{\circ} 25^{\prime} \mathrm{O}\right)$.

\section{3b. Selva baja de ja'abin}

Descripción. Comunidad dominada (> 30\%) por ja'abin (Piscidia piscipula) con altura promedio entre 10 y $15 \mathrm{~m}$. Especies dominantes. Bursera simaruba, Gymnopodium floribundum, Piscidia piscipula y Spondias mombin (cuadro 2).

Distribución. Las comunidades primarias están ampliamente distribuidas en el extremo norte de la meseta y en la ladera noroccidental y nororiental, en lugares planos, extremadamente rocosos, con suelos rojos (lateríticos). Las comunidades secundarias se localizan en lugares con fuerte alteración de extracción de madera o por agricultura y fuego, donde las comunidades primarias fueron selvas medianas o altas subperennifolias y palmares. Esta asociación está ampliamente distribuida al norte de la región de estudio y se ha observado que es común al este y oeste de Hopelchén, así como entre Ukum y Dzibalchén.

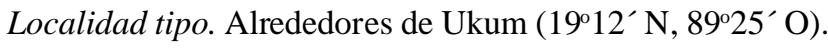

\section{3c. Selva baja de yaytil}

Descripción. Son comunidades dominadas por yaytil (Gymnanthes lucida), con una altura promedio de entre $5 \mathrm{y}$ $10 \mathrm{~m}$. Los fustes rectos de esta especie de lento crecimiento son muy atractivos para la gente de la localidad, por lo que también está altamente afectada por la extracción cerca de las poblaciones humanas.

Especies dominantes. Bursera simaruba, Gliricidia maculata, Gymnanthes lucida y Pseudobombax ellipticum (cuadro 2). Variantes. Existe una variante de selvas medianas subperennifolias (entre 12 y $18 \mathrm{~m}$ ), con dominancia de yaytil, que se localiza en los filos y las cimas de los cerros de la región sureste, donde los suelos son prácticamente inexistentes y con afloramientos de cal o de yeso. Generalmente está rodeada por selvas altas perennifolias y medianas subperennifolias. Esta asociación persiste en los lugares más aislados y de difícil acceso. Otra variante se presenta en la ladera occidental, al norte de la zona arqueológica de Calakmul, en lugares relativamente planos, pero con suelo pedregoso. Esta variante está dominada por Licaria coriacea, la cual tiene una fisonomía muy similar al yaytil.

Distribución. Ocupan cimas y laderas de cerros con yeso aflorante. Esta asociación se presenta como subcaducifolia en la cima y en pendientes muy pronunciadas de los cerros, y como subperennifolia en laderas con pendiente moderada o suave y con suelo escaso. Aunque su distribución es amplia, se encuentra restringida a las cimas, filos y laderas, y es fácilmente alterada por el fuego.

Localidad tipo. $5 \mathrm{~km}$ al noreste del ejido Narciso Mendoza, camino al poblado El Manantial $\left(18^{\circ} 15^{\prime} \mathrm{N}, 8^{\circ} 27^{\prime} \mathrm{O}\right)$. 


\section{3d. Selva baja de chicle.}

Descripción. Son comunidades con árboles dominantes de chicle o sapote (Manilkara zapota), de entre 6 y $15 \mathrm{~m}$. El porcentaje de especies que pierden las hojas varía entre subcaducifolio (entre 50 y $75 \%$ ) y subperennifolio (entre 25 y 50\%). El porcentaje de especies caducifolias parece estar en estrecha relación con el desarrollo del suelo. Las selvas subcaducifolias se encuentran en suelos poco desarrollados o con pendientes pronunciadas, o en sitios con yeso aflorante. Las selvas subperennifolias se encuentran en suelos más desarrollados o sitios con pendientes ligeras.

Especies dominantes. Bursera simaruba, Caesalpinia gaumeri, Canella winterana, Manilkara zapota, Pouteria campechiana y $P$. reticulata (cuadro 2).

Distribución. Se distribuyen en la parte occidental de la meseta y en los cerros con pendientes moderadas de la ladera y la planicie noroccidentales, en lugares con suelo poco desarrollado, en pendientes pronunciadas o con un proceso cársico acentuado, y en lugares con periodos cortos de inundación y rápida sequía.

Localidad tipo. $17 \mathrm{~km}$ al este de ejido Carlos Salinas de Gortari $\left(19^{\circ} 12^{\prime} \mathrm{N}, 89^{\circ} 58^{\prime} \mathrm{O}\right)$.

\section{Bajos}

Comunidades subperennifolias a caducifolias de árboles o arbustos de 4 a $8 \mathrm{~m}$ de altura promedio, en sitios periódicamente inundados durante dos a seie meses. No se encuentran en depresiones en donde hay corrientes de agua temporales. La composición es muy variable con cambios contrastantes entre los bajos de la meseta y los de ambas laderas (cuadro 2). El bajo mixto ocupa la mayor extensión en la meseta y en la ladera occidental, mientras que los bajos de pukte' están restringidos a las planicies nororiental, suroriental y suroccidental. Estos bajos son los predominantes. El bajo de ts'iits'il che' se encuentra en la ladera centro y noroccidental, en manchones aislados, mientras que el bajo de chechem negro se distribuye en la planicie oriental.

\section{4a. Bajo mixto}

Descripción. Son comunidades de zonas inundables. Tres asociaciones de bajo están agrupados en el bajo mixto: bajos dominados por Cameraria latifolia, bajos dominados Hematoxylum campechianum y bajos con varias especies codominantes.

Especies dominantes. Las principales especies son Ateleia gummifera, Bravaisia berlandieriana, Bucida buceras, Byrsonima bucidaefolia, Cameraria latifolia, Coccoloba cozumelensis, Cordia dodecandra, Croton icche, Diospyros bumelioides, Erythroxylum rotundifolium, Eugenia winzerlingii, Eugenia spp., Haematoxylum campechianum, Lonchocarpus xuul, Metopium brownei y Manilkara zapota (cuadro 2).

Especies restringidas. Esta comunidad incluye varias especies de distribución restringida como elementos notables: Beaucarnea pliabilis, Byrsonima bucidaefolia, Caesalpinia gaumeri, Clusia flava, Cordia dodecandra, Diospyros bumelioides, Exothea diphylla, Gliricidia maculata, Haematoxylum campechianum, Hyperbaena winzerlingii, Jatropha gaumeri, Lonchocarpus xuul, Malpighia lundellii, Platymiscium yucatanum, Talisia floresii y Thevetia gaumeri. Distribución. Se distribuyen en los valles inundables de la meseta y en la ladera occidental, en suelos gley con alto contenido de yeso. Durante la época de lluvias se inundan pero durante el estío pierden el agua, formándose grietas en el suelo.

Localidad tipo. $1.5 \mathrm{~km}$ al norte de Zoh-Laguna $\left(18^{\circ} 36^{\prime} \mathrm{N}\right.$, $\left.89^{\circ} 25^{\prime} \mathrm{O}\right)$.

\section{4b. Bajo de pukte'}

Descripción. Son comunidades de árboles y arbustos con una altura promedio de 5 a $10 \mathrm{~m}$. Están dominados por pukte' (Bucida buceras), que alcanza hasta un 50 o $60 \%$ de dominancia.

Especies dominantes. Bucida buceras (cuadro 2).

Especies muy abundantes. Byrsonima bucidaefolia, Cordia dodecandra, Diospyros bumelioides, Gliricidia maculata, Haematoxylum campechianum, Hyperbaena winzerlingii, Lonchocarpus xuul, Malpighia lundellii, Platymiscium yucatanum, Sabal yapa, Thevetia gaumeri y Talisia floresii. Distribución. Se encuentran principalmente en las planicies nororiental, suroriental y suroccidental, en valles inundables con suelos gley.

Localidad tipo. Entre el ejido Dos Aguadas y ejido El Tesoro $\left(18^{\circ} 08^{\prime} \mathrm{N}, 8^{\circ} 10^{\prime} \mathrm{O}\right)$.

\section{Asociaciones poco representadas}

Las siguientes asociaciones aunque representan extensiones muy pequeñas, son fisonómicamente diferentes de las anteriores.

\section{Palmares}

Existen tres asociaciones en donde las palmas representan el elemento dominante: palmar de coyol, corozal y tasistal.

\section{5a. Palmar de coyol}

Descripción. Asociación rara, dominada por la palma de coyol o tuk (Acrocomia mexicana), con una altura promedio de 15 $\mathrm{m}$. Se desarrolla en laderas rocosas de poca pendiente. Esta comunidad es afectada periódicamente por fuego.

Especies dominantes. Acrocomia mexicana.

Distribución. Registrada en una sola localidad en los alrededores de Ich-ek, en la planicie nororiental.

Localidad tipo. $1 \mathrm{~km}$ al oeste del poblado Ich-ek $\left(19^{\circ} 10^{\prime} \mathrm{N}\right.$, $\left.89^{\circ} 12^{\prime} \mathrm{O}\right)$.

\section{5b. Corozal.}

Descripción. Asociación dominada por la palma corozo 
(Orbignya cohune), de aproximadamente 30 a $35 \mathrm{~m}$ de altura promedio. Las hojas de esta palma alcanzan hasta $12 \mathrm{~m}$ de longitud.

Especies dominantes. Orbignya cohune.

Distribución. Se distribuye principalmente en la planicie suroriental y en menor proporción en la planicie nororiental, en suelos pesados (rendzinas con deficiencia de drenaje). Originalmente cubrió extensiones amplias, pero ha sido altamente modificada por actividades agropecuarias. Al contrario de lo que ocurre en otras zonas del país, en donde estos palmares son mantenidos para utilizar los frutos y las hojas, en esta zona han sido extensamente destruidos. En la actualidad quedan pocas áreas con esta asociación, y además se encuentran en estado de alta perturbación.

Localidad tipo. En el límite norte entre los ejidos Carlos A. Madrazo y Nuevo Veracruz $\left(18^{\circ} 02^{\prime} \mathrm{N}, 8^{\circ} 15^{\prime} \mathrm{O}\right)$.

\section{5c. Tasistal}

Descripción. Asociación restringida dominada por la palma tasiste' (Acoelorraphe wrightii), de $4 \mathrm{~m}$ de altura en promedio. Varias de las especies presentes en esta asociación se distribuyen más ampliamente en selvas húmedas y en los alrededores de manglares.

Especies dominantes. Acoelorraphe wrightii.

Distribución. Se distribuye en áreas de suelos gravosos, con drenaje deficiente, en la planicie suroriental. Generalmente se encuentra distribuida como islas en medio de sabanas de nance. En otras partes del país el tasiste' (Acoelorraphe wrightii) es muy abundante en las sabanas inundables de la planicie costera del Golfo de México y en la costa de la península de Yucatán, en particular en sitios cercanos a manglares; también se encuentra en asociaciones de masas puras.

Localidad tipo. Margen noreste de la laguna de Alvarado $\left(18^{\circ} 01^{\prime} \mathrm{N}, 89^{\circ} 16^{\prime} \mathrm{O}\right)$.

\section{Sabanas}

Existen dos asociaciones en donde el estrato herbáceo es dominante: la sabana húmeda de ciperáceas y la sabana seca.

\section{6a. Sabana húmeda de ciperáceas}

Descripción. Es una comunidad herbácea de entre 1 y $1.5 \mathrm{~m}$ de altura, dominada por ciperáceas (Cyperus spp.). En ocasiones se encuentran algunos elementos arbóreos dispersos. Permanece inundada entre seis y ocho meses al año.

Especies dominantes. Cladium jamaicense, Cyperus articulatus, Fuirena stephani y otras ciperáceas.

Variantes. Existen comunidades dominadas por carrizo (Chusquea sp.), en el centro de un bajo localizado entre la central chiclera Villahermosa y la zona arqueológica de Calakmul.

Distribución. Se distribuye en la meseta y en la ladera y la planicie de la zona oriental, en lagunas azolvadas con suelos gley. Recientemente se han documentado varias especies nuevas y registros que amplían la distribución de diversas especies en esta sabana.

Localidad tipo. $5 \mathrm{~km}$ al este de X-Pujil (183’N, $\left.9^{\circ} 20^{\prime} \mathrm{O}\right)$.

\section{6b. Sabana seca.}

Descripción. Comunidades dominadas por hierbas con abundantes elementos arbustivos. En algunas los arbustos están dominados por el nance (Byrsonima crassifolia), mientras que en otras hay gran variedad de especies. Las hierbas son abundantes y muy diversas, incluyendo plantas de $2 \mathrm{~cm}$ de tamaño como Drosera $\mathrm{sp}$., de $5 \mathrm{~cm}$ de tamaño como algunas gramíneas y utricularias, y otras especies de $10 \mathrm{~cm}$ a $1 \mathrm{~m}$ de altura como varias gramíneas y ciperáceas. Varias de las especies en esta asociación presentan hábitos carnívoros en respuesta a los suelos ácidos deficientes en nitrógeno.

Especies dominantes. Los elementos arbóreos son: Acoelorraphe wrightii, Byrsonima bucidaefolia, Byrsonima crassifolia, Coccoloba cozumelensis, Eugenia ibarrae, Manilkara zapota y Metopium brownei.

Variantes. Alrededor de la sabana seca y en transición con las selvas contiguas se encuentra una asociación dominada por Terminalia amazonia, de entre 12 y $25 \mathrm{~m}$ de altura. Es una asociación difícil de reconocer y fácil de confundir con la selva de pukte' por la similitud entre el aspecto de las dos especies.

Distribución. Se distribuyen en la ladera oriental, en lugares con pendiente moderada y lugares planos, sobre suelos arenoso-gravosos o con alta acumulación de sales. En la época de lluvias el suelo se satura y en la época de secas pierde totalmente la humedad. En la ladera nororiental esta asociación es conocida como "blanquizal".

Localidad tipo. $9 \mathrm{~km}$ al sureste del ejido Dos Naciones, camino a El Civalito $\left(17^{\circ} 55^{\prime} \mathrm{N}, 89^{\circ} 20^{\prime} \mathrm{O}\right)$.

\section{Asociaciones de origen secundario}

Entre las comunidades secundarias de selva se pueden reconocer tres asociaciones generales. La selva de tsalam ocupa la mayor extensión, seguida por la de chaká y finalmente la de xu'ul.

\section{7a. Selva de tsalam}

Descripción. Comunidad con elementos dominantes de entre 10 y $20 \mathrm{~m}$ de altura. La temporada caducifolia de los elementos dominantes es relativamente corta y dura de un mes y medio a dos meses, ya que el tsalam (Lysiloma latisiliqua) produce hojas en abril; en algunos lugares es dominante hasta en un $90 \%$.

Especies dominantes. Lysiloma latisiliqua.

Distribución. Se localiza en lugares en donde previamente existían selvas subcaducifolias y subperennifolias que generalmente fueron transformadas por fuego. Se establecen en lugares con roca suelta y suelo somero o inexistente. Es 
una comunidad de amplia distribución en el noreste de la meseta y en general en los alrededores de los poblados.

Localidad tipo. $7 \mathrm{~km}$ al norte del poblado Bel-ha $\left(19^{\circ} 02^{\prime} \mathrm{N}\right.$, $\left.89^{\circ} 19^{\prime} \mathrm{O}\right)$.

\section{7b. Selva de chaka'}

Descripción. Comunidad en lugares en donde se presentan incendios que destruyen parcialmente a las comunidades primarias. La altura de esta comunidad varía de 6 a $20 \mathrm{~m}$. Dependiendo de la proporción de chaká (Bursera simaruba), que es la especie dominante, hay una mayor o menor proporción de pérdida de hojas, con un comportamiento de caducifolia a subperennifolia. En algunos lugares cubren grandes extensiones, que generalmente coinciden con zonas en donde se registró una extracción selectiva de madera o grandes incendios.

Especies dominantes. Bursera simaruba.

Distribución. Esta comunidad es rara en lugares planos y abundante en lugares con pendientes ligeras o fuertes sobre suelos rocosos, con poco o moderado desarrollo, principalmente en la parte central de la ladera oriental.

Localidad tipo. Entre 5 y $10 \mathrm{~km}$ al norte del ejido Los Angeles, camino al ejido La Lucha $2\left(18^{\circ} 17^{\prime} \mathrm{N}, 8^{\circ} 12^{\prime} \mathrm{O}\right)$.

\section{7c. Selva de xu'ul}

Descripción. Comunidad con altura promedio extremadamente variable que va desde matorrales de $2 \mathrm{~m}$ en lugares derivados de bajos, hasta selvas de $20 \mathrm{~m}$. El xu'ul (Lonchocarpus xuul) domina la comunidad entre 30 y $50 \%$. Los árboles de xu'ul envejecen rápidamente y en lugares con alteración documentada entre 20 y 30 años se observa una alta mortalidad de árboles maduros que son sustituidos por otras especies. El elemento caducifolio parece estar relacionado con la humedad de los suelos, ya que en lugares con alta humedad relativa en el aire, el periodo caducifolio es corto y antecede a la floración, que ocurre al final de la temporada de secas.

Especies dominantes. Lonchocarpus xuul.

Variantes. En el centro de la meseta se encuentra una variante parecida a esta asociación secundaria dominada por Nectandra coriacea, de 10 a $12 \mathrm{~m}$ de altura.

Distribución. Generalmente se encuentra a lo largo de la meseta y ladera oriental, en lugares inundables o de drenaje deficiente. Es una comunidad muy común en las zonas en donde hay influencia antropogénica.

Localidad tipo. Jardín Botánico de Zoh-Laguna (18³6’ N, $\left.89^{\circ} 25^{\prime} \mathrm{O}\right)$.

\section{7d. Bajo de ts'iits'il che'/ chechem negro}

Descripción. Son comunidades de origen secundario en el área de estudio, aunque pueden encontrarse como comunidades primarias en el centro y sur de Quintana Roo. Se desarrollan en zonas de bajos mixtos o de pukte' que son alterados y alcanzan una altura promedio de entre 5 y $15 \mathrm{~m}$.
Especies dominantes. Sak ts'iits'il che' (Gymnopodium floribundum) y chechem negro (Metopium brownei).

Especies con distribución restringida. Byrsonima bucidaefolia, Clusia flava, Cordia dodecandra, Diospyros bumelioides, Exothea diphylla, Gliricidia maculata, Haematoxylum campechianum, Hyperbaena winzerlingii, Jatropha gaumeri, Lonchocarpus xuul, Malpighia lundellii, Platymiscium yucatanum, Thevetia gaumeri y Thouinia paucidentata.

Distribución. Estos bajos incluyen dos asociaciones dominadas por especies diferentes. Los bajos dominados por Gymnopodium floribundum se encuentran en el centro y norte de la meseta, incluyendo ambas laderas, en suelos pedregosos. Los bajos dominados por Metopium brownei se encuentran principalmente en la planicie oriental en suelos de gley.

Localidad tipo. De chechem negro, $4 \mathrm{~km}$ al este del ejido Dos Aguadas ( $\left.18^{\circ} 08^{\prime} \mathrm{N}, 89^{\circ} 07^{\prime} \mathrm{O}\right)$;

de sak ts'iits'il che', $4 \mathrm{~km}$ al suroeste del $\mathrm{km} 34$ de la carretera a la zona arqueológica de Calakmul $\left(18^{\circ} 17^{\prime} \mathrm{N}, 8^{\circ} 53^{\prime} \mathrm{O}\right)$.

\section{7e. Acahual}

Descripción. Comunidades sucesionales de diversas edades presentes en sitios afectados por agricultura, tala e incendios. Especies dominantes. Están compuestos por una gran variedad de especies, entre las cuales son comunes y abundantes: Acacia gaumeri, Bursera simaruba, Cecropia peltata, Croton icche, Gymnopodium floribundum, Hampea trilobata, Lonchocarpus xuul, Lysiloma latisiliqua, Metopium brownei, Mimosa bahamensis, Piscidia piscipula, Pteridium aquilinum y Viguiera dentata.

Distribución. Su distribución es muy amplia y en general se encuentran en la cercanía a poblados o a centrales chicleras. Localidad tipo. Ranchos de la carretera entre X-Pujil y La Moza $\left(18^{\circ} 28^{\prime} \mathrm{N}, 89^{\circ} 18^{\prime} \mathrm{O}\right)$.

\section{7f. Helechal o crespillal}

Descripción. Comunidades dominadas casi exclusivamente por el crespillal (Pteridium aquilinum). Se establecen en suelos muy degradados que han sido utilizados varias veces para agricultura o ganadería. La comunidad es favorecida por los fuegos anuales que la mantienen, impidiendo la sucesión.

Especies dominantes. Pteridium aquilinum.

Especies restringidas. Sabal yapa es la única especie con distribución restringida que se encuentra en los helechales.

Distribución. Se pueden observar extensiones amplias de esta comunidad en la ladera oriental.

Localidad tipo. $5 \mathrm{~km}$ al sur del ejido San Antonio Soda (18 $23^{\prime}$ $\left.\mathrm{N}, 89^{\circ} 08^{\prime} \mathrm{O}\right)$.

\section{Discusión}

Las selvas de la región de Calakmul se consideran marginales debido a la combinación de condiciones climáticas, edáficas 
y latitudinales. Los factores determinantes de la distribución de la vegetación en esta región son principalmente la precipitación escasa y variable, el sustrato geológico particular y el pobre desarrollo del suelo, los disturbios naturales y la historia de las actividades humanas. A continuación discutimos estos factores.

Precipitación. Los patrones regionales de precipitación influyen sobre la distribución a gran escala de las asociaciones vegetales. La región presenta una baja precipitación (promedio de $1076.2 \mathrm{~mm}$ ) en comparación con otras comunidades de selvas húmedas, con fuerte estacionalidad y con alta variabilidad interanual (intervalo: 552--1634 mm;
A diferencia de la porción norte de la península en donde la topografía plana tiene poca influencia sobre los aspectos climáticos, en el área de estudio la meseta de Zoh-Laguna, cuya altitud promedio es de $250 \mathrm{~m}$ y con elevaciones de hasta $385 \mathrm{~m}$, crea una sombra orográfica en las laderas y planicies occidentales, al interceptar los vientos húmedos dominantes del sureste. Esta sombra de lluvia ocasiona que en el noroeste se encuentren las selvas bajas y medianas con especies características de zonas de baja precipitación y con comportamiento deciduo.

La extrema variabilidad interanual en la precipitación en la región (figura 4) produce cambios drásticos en la fenología, por lo que las asociaciones pueden cambiar en su

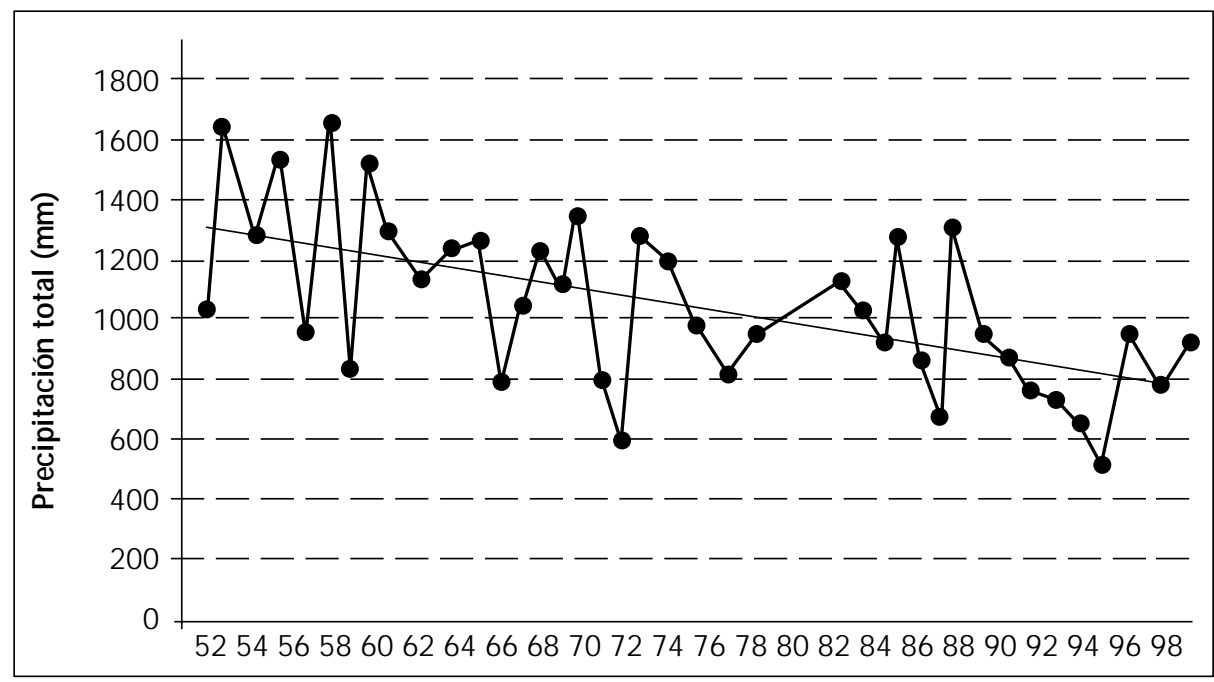

Figura 4. Variabilidad interanual de la precipitación y tendencia entre 1953 y 1997 de la Estación Meteorológica Zoh-Laguna, Campeche (Comisión Nacional del Agua, 1997)

figura 4). La precipitación promedio para el desarrollo de las selvas altas se ha considerado como de $1600 \mathrm{~mm}$ anuales bien distribuidos o $60 \mathrm{~mm}$ mensuales (Pennington y Sarukhán, 1998) o de 1000 a 1200 mm en lugares protegidos (Rzedowski, 1978). En condiciones más secas ya no se desarrollan selvas sino matorrales xerófitos o sabanas, dependiendo de la región. Los vientos dominantes provenientes del Caribe producen un gradiente de precipitación de sureste a noroeste en la península de Yucatán (White y Darwin, 1995). En la región de Calakmul se aprecia la transición de las zonas húmedas a las secas, particularmente de ambos lados de la meseta de Zoh-Laguna. En el sureste, en donde la precipitación es mayor, se encuentran las selvas mejor desarrolladas o altas (> $30 \mathrm{~m}$ de altura). En cañadas muy restringidas, con exposición norte, este tipo de vegetación presenta un comportamiento perennifolio y representa el límite norte de las selvas altas perennifolias en la península de Yucatán. comportamiento fenológico de subperennifolio o caducifolio, dependiendo de las condiciones climáticas de cada año.

Suelos. A lo largo del gradiente sureste-noroeste de precipitación expuesto anteriormente, el grado de desarrollo del suelo, altamente influenciado por la topografía, determina el mosaico de asociaciones vegetales. Debido a la gran permeabilidad del sustrato cársico, los suelos no retienen humedad. Los procesos de disolución impiden la acumulación de agua superficial o la presencia de corrientes superficiales permanentes. Los suelos de la región derivan de rocas calizas carbonatadas y sulfatadas. Los carbonatos son un factor limitante para muchas especies de árboles que no pueden metabolizar el calcio (Wendt, 1989), mientras que los sulfatos (yeso) retienen el agua, propiciando una aridez fisiológica en las raíces de las plantas (Rzedowski, 1978; Turner y Powell, 1979).

El afloramiento de yeso concentrado en la meseta de Zoh- 
Laguna es único en México y Centroamérica registrado en clima tropical. Generalmente por la alta afinidad con el agua, estos afloramientos se disuelven muy rápidamente (AguilarNogales, 1981). El grosor de las capas de yeso alcanza hasta $40 \mathrm{~m}$ de profundidad, con una pureza de entre 40 y $96 \%$ (Aguilar-Nogales, 1981). Entre las especies arbóreas que han tenido éxito bajo estas condiciones limitantes se encuentran varias especies de la familia Sapotaceae. Estas especies tienen una fisiología adaptada a metabolizar el calcio (Wendt, 1989; Pennington, 1990). Además, su látex les permite soportar la aridez fisiológica. De hecho, debido a la diversidad de especies de esta familia (Dugelby, 1998), la península de Yucatán se considera un centro de especiación secundario de la familia (Pennington, 1990). Tanto la selva baja caducifolia como el bajo mixto son asociaciones que cubren amplias extensiones en este tipo de substrato.

En la zona sur, donde la precipitación es mayor, las diferencias en el desarrollo del suelo y la calidad del drenaje tienen una fuerte influencia sobre la distribución de las asociaciones. En suelos bien desarrollados con buen drenaje se presentan selvas altas y medianas de chicle y ramón. El chicle predomina en las laderas y en sitios menos húmedos, mientras que la predominancia del ramón se da en sitios más pedregosos y húmedos, en las cimas de los cerros. Los ramonales a menudo se encuentran asociados a sitios arqueológicos. En las zonas con mal drenaje predominan
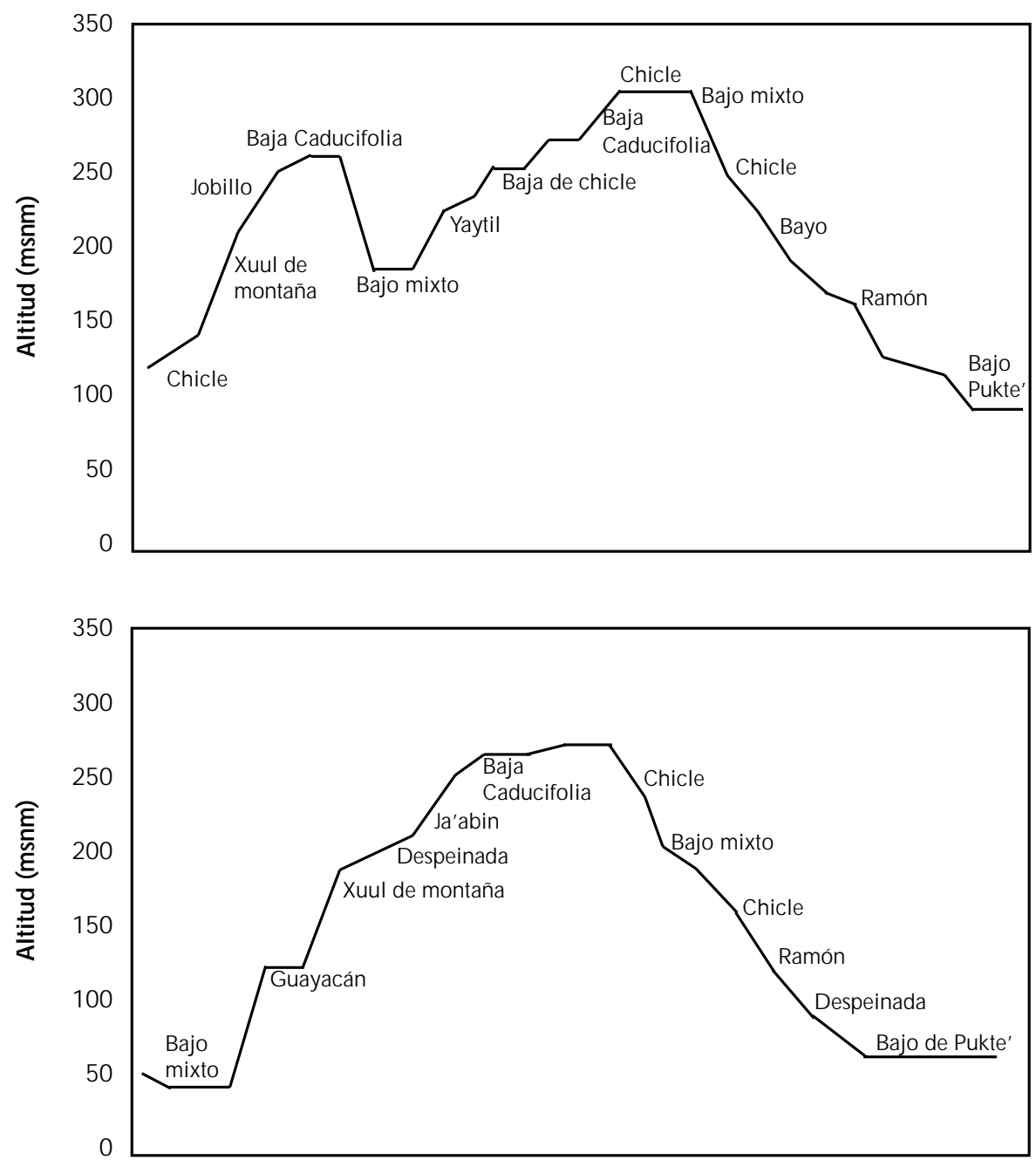

Figura 5. Perfiles esquemáticos de la distribución de las asociaciones vegetales en dos transectos latitudinales en el sur: A (Lat. $\left.18^{\circ} 00^{\prime}\right)$ y norte B ( $\left.19^{\circ} 00^{\prime}\right)$ del área de estudio. 
pukte' y bayo, la primera especie en los suelos con mayor proporción de arcilla (figura 5).

En la zona con menor precipitación se encuentran las selvas medianas subcaducifolias. La selva de xu'ul de montaña y la de guayacán se encuentran en suelos con buen drenaje, mientras que la selva de despeinada se localiza en suelos con mal drenaje. La selva de jobillo se presenta principalmente en suelos pedregosos (figura 5).

En los sitios con poco desarrollo de suelo o donde el clima es más seco se desarrollan las selvas bajas. La selva baja caducifolia se presenta como una franja en el centro de la región, en lugares en donde los suelos son someros y bajo la influencia de la sombra de lluvia originada por la meseta de Zoh-Laguna. Las selvas de ja'abin también se encuentran en suelos someros pero con alta oxidación (suelos rojos). Las selvas (bajas) de chicle se presentan en las laderas de la meseta en sitios con suelo somero. Las selvas de yaytil se distribuyen en la zona sur, pero en donde los suelos son muy someros y altamente pedregosos (figura 5).

Los bajos se localizan en las pequeñas cuencas endorreicas, en donde el agua se estanca formando encharcamientos estacionales, y tienen una amplia distribución en la región. El bajo de pukte' se localiza en las cuencas bajas, particularmente en el límite con Belice y Quintana Roo, mientras los bajos mixtos se encuentran en las partes elevadas de la meseta (figura 5).

Los palmares (corozal y tasistal) cubren en pequeñas extensiones en suelos con mal drenaje en algunas cañadas del sureste. Los palmares de coyol se distribuyen en el noreste en sitios con mal drenaje, sobre declives muy suaves. Las sabanas secas se encuentran en sitios con suelos ácidos sobre lomeríos con pequeños afloramientos de cuarzo. Las sabanas húmedas se localizan en cuencas endorreicas inundadas la mayor parte del año.

Las relaciones entre las asociaciones vegetales, la topografía y el suelo han sido documentadas recientemente para el Parque Nacional Tikal, en Guatemala, $60 \mathrm{~km}$ al sur de nuestra área de estudio (Schulze y Whitacre, 1999). Aunque Tikal se encuentra en una región con mayor precipitación (1,300 a 1,500 mm), mayor altitud (160 a 400 m) y el estudio comprende un área relativamente pequeña $\left(153 \mathrm{~km}^{2}\right)$, existen varias equivalencias entre las comunidades descritas en ambos trabajos y sus relaciones ambientales (cuadro 1). Siete comunidades son compartidas por ambos estudios. La región de Tikal se encuentra en la porción sur de la provincia florística de Yucatán y representa condiciones más húmedas dentro del gradiente continuo de precipitación, por lo que las comunidades con requerimientos más altos de humedad sólo se restringen a Tikal, mientras que las comunidades más secas se restringen a Calakmul.

Las comunidades con requerimientos más altos de humedad como el "mesic upland forest" equivalente a una selva alta perennifolia, están restringidas a algunas cañadas del sureste de la región de Calakmul y podrían ser equivalentes a la selva mediana de bayo. Varias de las especies dominantes en Tikal como Pouteria amygdalina del "standard upland forest," y Ampelocera hottlei y Pseudolmedia oxyphyllaria del "mesic upland forest" han sido recientemente registradas para la porción mexicana de la península de Yucatán (Martínez et al., 2001). Todas estas especies se registraron en el sureste del área de estudio que representa la zona más húmeda. Otras especies dominantes del "mesic upland forest", como Exothea paniculata y Vatairea lundellii aún no han sido registradas. La palma sabal (Sabal mauritiiformis), que forma asociaciones en Tikal, es abundante en algunos lugares de Calakmul, pero no es dominante en ninguna asociación.

Latitudinalmente, las selvas de la región de Calakmul se consideran marginales ya que en esta zona las temperaturas pueden disminuir hasta $0^{\circ} \mathrm{C}$, limitando los requerimientos de muchas especies (E. Martínez-Salas, obs. pers).

Disturbios naturales. Los principales disturbios naturales que modifican las características de la vegetación en la región son los huracanes, los incendios y las sequías. Los huracanes producen lluvias intensas concentradas en un periodo corto, que arrastran gran cantidad de suelo y crean inundaciones en las partes bajas. Los huracanes llegan periódicamente a la península de Yucatán durante los meses de agosto y septiembre (a veces octubre y noviembre), afectando principalmente los árboles del dosel, tirando árboles emergentes y árboles muertos en pie. En el área de estudio los efectos de los huracanes son notables en las laderas orientales de la meseta de Zoh-Laguna. En estos sitios se presentan selvas húmedas pero con dosel relativamente bajo $(<25 \mathrm{~m}) \mathrm{y}$ carentes de individuos emergentes.

Los huracanes, además, aumentan la cantidad de materia orgánica en el suelo (hojas, ramas, troncos) (Whigham et al., 1990, 1991), incrementando las posibilidades de incendios en años subsecuentes si se presenta un estío acentuado. La tendencia de disminución de la precipitación documentada por la estación meteorológica Zoh-Laguna, sugiere que la región está sufriendo un proceso gradual de aridez que ha disminuido la precipitación promedio de alrededor de 1,300 $\mathrm{mm}$ en la década de 1950 a $790 \mathrm{~mm}$ en la década de 1990 (figura 4). La tendencia de aridez de la región aumenta las probabilidades de incendios a gran escala.

Otra característica de la región es la alta variabilidad en la precipitación total anual, que alcanza máximos por arriba de los $1,600 \mathrm{~mm}$ y mínimos por debajo de los $600 \mathrm{~mm}$. Por ejemplo, en 1994 sólo se registraron $552 \mathrm{~mm}$. Durante la temporada seca de 1998, muchas asociaciones vegetales que normalmente presentan un comportamiento subperennifolio perdieron completamente el follaje.

Factores antropogénicos. La vegetación de Calakmul también ha sido modificada fuertemente por factores antropogénicos a lo largo del tiempo. Esta región fue uno de los centros de 
desarrollo más importantes de los mayas de las tierras bajas, como lo atestigua el gran número de sitios arqueológicos importantes concentrados en el área, incluyendo Balamkú, Calakmul, Becán, X-Pujil, Chicanna, Hormiguero, y Río Bec, entre otros (Andrews, 1996). Los grandes asentamientos mayas permanecieron en la región por lo menos 2400 años (Carrasco, 1996). Se ha sugerido que la población humana en la región de Calakmul, que forma parte de las "tierras bajas centrales mayas", aumentó de 11 individuos $/ \mathrm{km}^{2}$, en 300 D.C. a un máximo de 117 a 151 individuos $/ \mathrm{km}^{2}$ quinientos años más tarde (Hodell et al., 1995). Es muy probable que durante el periodo clásico, a pesar de las prácticas agrícolas intensivas como la construcción de terrazas y campos inundables, gran parte de la vegetación haya sido removida para mantener esta alta población (Harrison, 1990; Andrews, 1996). De hecho, algunos autores han sugerido que la mayor parte de la selva había desaparecido antes de 300 D.C. (Pohl, 1985). Después de 800 D.C., la población disminuyó gradualmente hasta la desaparición de los Cehaches, últimos habitantes de la región, con economía basada en la agricultura y la elaboración de mantas de algodón, alrededor de 1600 (Carrasco, 1997), permitiendo la recolonización de la selva.

Es difícil interpretar las consecuencias de las actividades prehispánicas en la vegetación. Sin embargo, algunos autores han propuesto que la vegetación actual aún muestra consecuencias de este impacto. Por ejemplo, se ha sugerido que las actuales selvas inundables (bajos) son el resultado del azolvamiento de lagunas someras debido a las actividades agrícolas mayas (Miranda, 1958; Harrison, 1990).

La dominancia de ramón en sitios arqueológicos y sus alrededores también ha llevado a la sugerencia que esta especie, ampliamente utilizada por los mayas, fue particularmente favorecida (Standley, 1930). Sin embargo, otros autores sugieren que la abundancia de esta especie se debe principalmente a sus requerimientos (White y Darwin, 1995; Schulze y Whitacre, 1999).

Extracción de chicle. Después de más de 400 años de mínimo impacto humano, a finales del siglo antepasado se iniciaron una serie de actividades como la extracción del látex de Manilkara zapota y la explotación de maderas finas, duras y blandas, que han modificado el mosaico de vegetación de diversas formas y a varias intensidades. La extracción de chicle se inició desde finales del siglo XIX y hasta la década de 1960 la República Mexicana fue el principal productor de chicle en el mundo (Ponce, 1990).

La actividad de extracción de látex se llevó a cabo mediante el establecimiento de centrales chicleras (p. ej. Altamira, Bonfil, Villahermosa) que funcionaban como centros de acopio para mandar el producto en avioneta a los centros de exportación. La mayor actividad chiclera coincidió con la Segunda Guerra Mundial (Villaseñor, 1958), disminuyendo drásticamente debido a la producción de sustitutos sintéticos (Dugelby, 1998). A partir de 1994 la explotación ha continuado de manera baja e irregular (figura 6, a).

La extracción de látex se lleva a cabo a finales de la estación lluviosa, cuando la concentración de látex es mayor y fluye por debajo la corteza. Los individuos utilizados se dejan descansar por un periodo de siete a ocho años. Los efectos de la explotación chiclera en la mortalidad de los

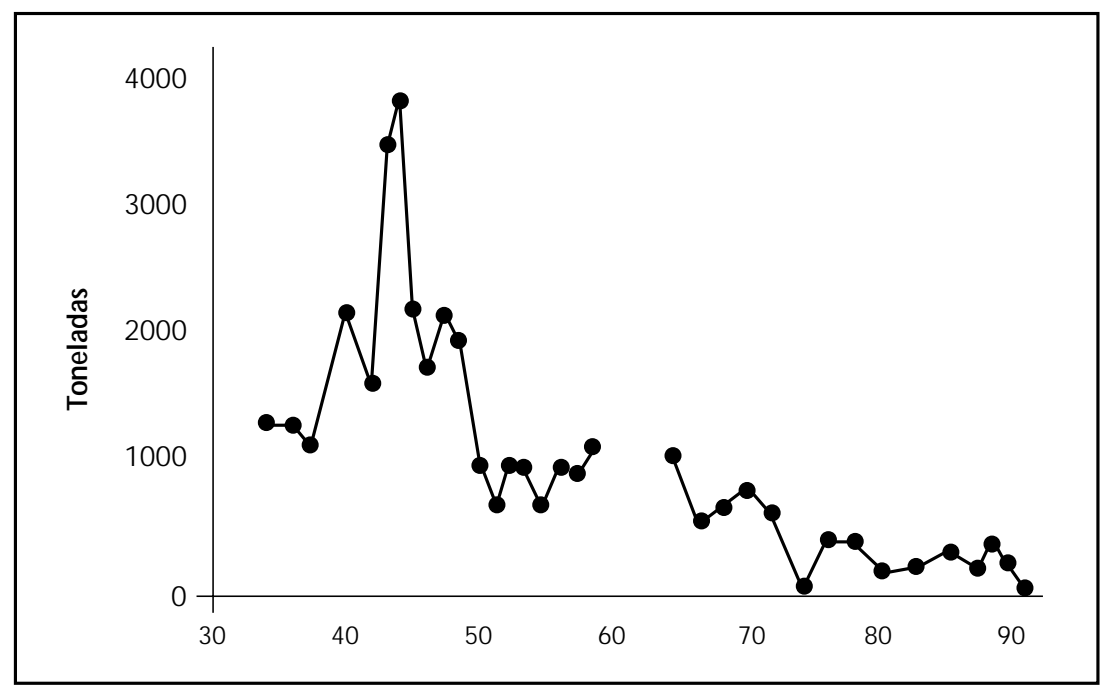

Figura 6a. Producción de chicle en el estado de Campeche (1936-1998) 


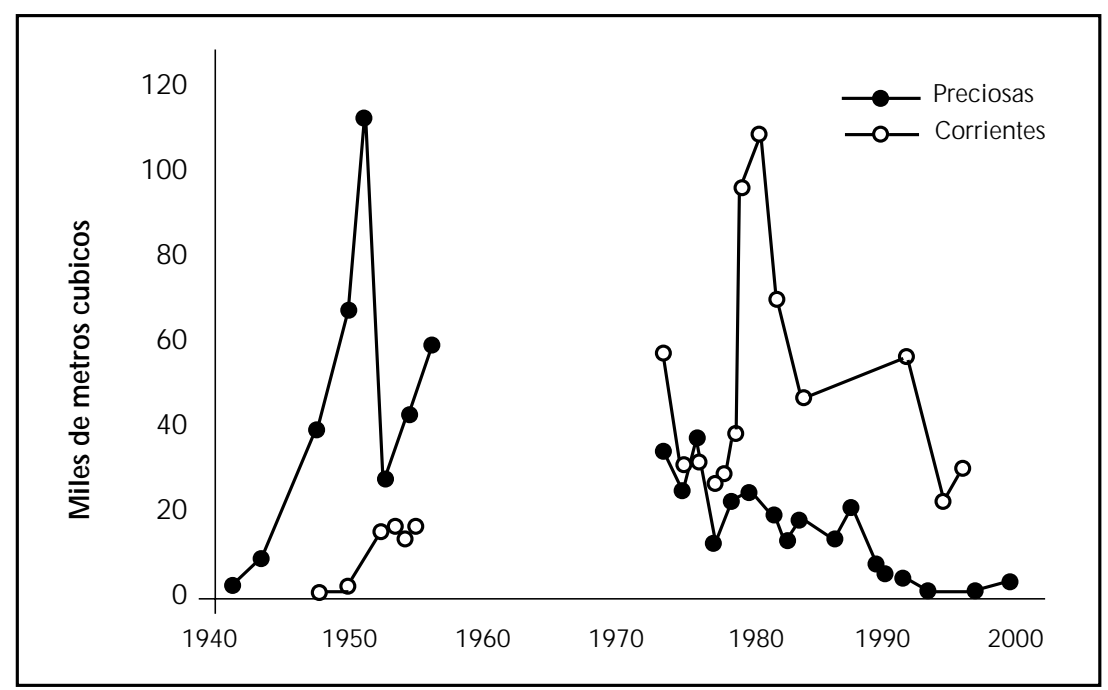

Figura 6b. Producción de madera en el estado de Campeche (1936-1998)

árboles han sido discutidos. Algunos autores mencionan que esta actividad es negativa para los individuos, afectando hasta a un $30 \%$ de la población (Villaseñor, 1958), mientras que otros opinan que el efecto de las actividades chicleras es bajo (Lundell, 1937; Miranda, 1958). El efecto de esta actividad sobre la mortalidad de los árboles depende en gran medida de la experiencia de los chicleros y de la disponibilidad de árboles adecuados. A medida que disminuye el número de chicleros con experiencia, los nuevos chicleros elevan la tasa de mortalidad al hacer incisiones demasiado profundas en los árboles (comunicación personal de los chicleros). Asimismo la disminución de árboles de diámetros adecuados propicia la utilización de árboles de menor diámetro, los cuales se debilitan más fácilmente. Otro efecto de la extracción de látex es la ausencia de fructificación de los árboles utilizados durante dos o tres años posteriores a la extracción (E. Martínez-Salas, obs. pers.). Por otra parte, debido a la importancia de esta actividad, la extracción de madera de esta especie está vedada permanentemente (Villaseñor, 1958), lo que ha contribuido a que actualmente se encuentren poblaciones de sapote con individuos de gran diámetro.

Actividad maderera. La historia de la extracción de caoba y cedro en el estado de Campeche es similar a la de otras regiones de México (Snook, 1998). Se inició de manera formal a finales del siglo antepasado con el establecimiento de varias compañías extranjeras (Villaseñor, 1958; RevelMouroz, 1972). La extracción se formalizó en 1918, incrementándose en la década de 1940 y 1950, con una extracción mucho más alta de la primera especie. El promedio anual de extracción de maderas preciosas para el estado de
Campeche se triplicó de los años 40 (promedio anual 18,949 $\mathrm{m}^{3}, \mathrm{n}=8$ años) a los 50 (promedio anual $=76,248 \mathrm{~m}^{3}, \mathrm{n}=5$ años). Durante la actual década ha disminuido a un $3 \%$ del volumen extraído en la década de 1950 (promedio anual = $2,559 \mathrm{~m}^{3}, \mathrm{n}=3$ ). La actividad forestal ha resultado en la disminución drástica de estas especies y ha dejado grandes extensiones modificadas que aún se pueden reconocer por la extensa red de caminos y callejones abandonados y el mosaico de acahuales de diversas edades.

El aserradero de Zoh-Laguna fue establecido en los años 20, para la obtención de tabla de caoba, con una capacidad de producción de 20,000 $\mathrm{m}^{3}$ al año. A fines de la década de 1930 y principios de la de 1940 el aserradero adquirió un torno y una rebanadora con una capacidad de $8,000 \mathrm{~m}^{3}$ para obtener chapa de caoba. El segundo torno con un tamaño excepcional se estableció alrededor de 1955. Solamente existen otros dos tornos similares en el mundo (Brasil, Malasia) que aceptan diámetros de $2.5 \mathrm{~m}$ y con una capacidad de $15,000 \mathrm{~m}^{3}$. La producción de madera disminuyó drásticamente en 1991, cuando se terminó la concesión. Para esa fechas las maderas preciosas habían sido drásticamente reducidas debido a su sobrexplotación (D. Acopa, com. pers.; figura $6, \mathrm{~b})$. La región que contribuyó con la mayor proporción de maderas preciosas a la producción estatal en 1991 obtuvo una autorización de explotación de tan sólo 528 $\mathrm{m}^{3}$ de caoba al año, basada en la limitada existencia de esta especie.

Si la caoba es una especie favorecida por fuertes disturbios, ¿cómo es posible que fuera tan abundante en la región? Todavía durante los años 50 algunas de las selvas de la región estaban dominadas por caoba (Miranda, 1958). Los grandes individuos extraídos durante esos años pudieron haber 
germinado cientos de años antes. Esta especie tiene una escasa regeneración bajo condiciones naturales en bosques no perturbados en Chiapas (Miranda, 1951; Martínez et al., 1999), Campeche (Miranda, 1958) y Quintana Roo (Snook, 1998; Flachsenberg y Galletti, 1998). Su regeneración exhibe mayor éxito en zonas fuertemente perturbadas (Miranda, 1958; Snook, 1998; Martínez et al., 1999). Por lo tanto, disturbios naturales (huracanes e incendios) o las condiciones dejadas por los asentamientos mayas que existieron en el área por 2400 años (Carrasco, 1996) debieron haber propiciado las condiciones para el desarrollo de la caoba.

La intensa actividad de extracción de caoba y cedro ha resultado en la depauperación de las selvas de Calakmul. Actualmente es difícil encontrar grandes extensiones en donde la caoba sea una especie dominante, como fueron descritas hace 45 años (Miranda, 1958). Los individuos actuales generalmente se encuentran dispersos y tiene menos de $55 \mathrm{~cm}$ de diámetro, que es el limite mínimo de explotación. Los individuos de cedro son aún más raros (E. MartínezSalas y C. Galindo-Leal, obs. pers.). La construcción de la red de caminos y la remoción de los grandes árboles de caoba y cedro seguramente son responsables de la dominancia actual de ciertas especies (ver más adelante).

En la década de 1970 se inició la extracción de maderas duras como Chlorophora tinctoria, Cordia dodecandra, Guaiacum sanctum, Haematoxylon campechianum, Lonchocarpus castilloi, Lysiloma latisiliqua, Metopium brownei, Simira salvadorensis y Swartzia cubensis para la elaboración de durmientes.

Las maderas blandas como Bursera simaruba, Ceiba pentandra y Pseudobombax ellipticum son las especies actualmente más afectadas por la extracción forestal para la elaboración de chapa, abatelenguas, palillos, lápices y huacales. La extracción de maderas llamadas "corrientes" aumentó rápidamente de los años 40 (promedio anual =1,767 $\mathrm{m}^{3}, \mathrm{n}=2$ ), a los 50 (promedio anual $=14,325 \mathrm{~m}^{3}, \mathrm{n}=5$ ). Durante la década de 1990 casi se ha triplicado (promedio anual $=39,983 \mathrm{~m}^{3}, \mathrm{n}=3$ ) (figura $6, \mathrm{~b}$ ).

El guayacán (Guaiacum sanctum), conocido comercialmente como "lignum vitae", se utilizó para las chumaceras de barco debido a su alta densidad y dureza, y a sus aceites que actúan como autolubricantes. La extracción de guayacán disminuyó drásticamente a finales de los años 70 , cuando se obtenía un promedio de $2800 \mathrm{~m} 3$, a un promedio de $450 \mathrm{~m}^{3}$ en los años 80 . Actualmente el guayacán se utiliza como madera ornamental, aunque se encuentra en la lista de especies de uso restringido (SEMARNAT, 2002).

Colonización. El acceso proporcionado con la construcción de la carretera entre Escárcega y Chetumal en los años 70 aumentó las actividades en la región, facilitando la colonización de inmigrantes de varios estados de la República Mexicana (Pino, 1997). Las primeras comunidades que se asentaron en el área, involucradas principalmente en la extracción de chicle, recibieron grandes extensiones forestales. Los inmigrantes de olas recientes de colonización motivadas por diversas causas han recibido terrenos más pequeños. Las actividades productivas regionales incluyen actualmente el desarrollo urbano, la agricultura de roza, tumba y quema, el cultivo intensivo de chile, la ganadería incipiente, la extracción selectiva de madera, la extracción de chicle, la cacería de subsistencia y la apicultura (Escamilla et al., 2000). Estas actividades afectan la estructura y composición de las comunidades forestales en diversos grados. El análisis de la imagen de satélite Landsat TM de la región de 1995 indica que de un total de $23,398.17 \mathrm{~km}^{2}, 9.87 \%$ se ha convertido en zonas agrícolas o acahuales. Esta pérdida de la cubierta forestal se encuentra fuertemente concentrada en la planicie nororiental (X-Maben) y en la planicie centro y noroccidental (Yohaltún, Constitución) (Sandler et al., 1998).

Cambios en la vegetación en los últimos 45 años. El detallado trabajo de Miranda (1958) es de gran relevancia, ya que sus descripciones florísticas de las comunidades vegetales de la porción mexicana de la península, y en particular de la zona centro, fueron hechas durante el auge de la explotación de maderas preciosas (1954-55), cuando la caoba aún era una especie dominante y antes que las primeras comunidades humanas se asentaran en la región (década de 1960) (Pino, 1997). La comparación de las categorías de abundancia de especies consideradas por Miranda (1958) con nuestras observaciones cualitativas y cuantitativas indican una gran dinámica reciente en la composición florística del área (Galindo-Leal et al., 2000).

Especies que han aumentado considerablemente. Varias especies consideradas en este trabajo como abundantes y muy abundantes no habían sido reportadas dentro de estas selvas (Miranda, 1958) por diversas razones. Es de llamar la atención la abundancia actual de Bursera simaruba, no mencionada como abundante en las selvas de chicle relativamente húmedas de la región (Miranda, 1958). De igual manera, esta especie no es mencionada en las asociaciones inundables como tintales y en la asociación Cameraria-HaematoxylonMetopium, en donde actualmente es abundante. Esta especie es muy abundante en las selvas secas del norte de la península (White y Darwin, 1995) y está asociada a perturbaciones. La gran abundancia de Bursera simaruba en la zona de estudio parece ser un fenómeno reciente, consecuencia de las perturbaciones humanas. Coccoloba cozumelensis es otra especie que también parece haber aumentado debido a las perturbaciones. El guano yucateco es una especie que es mantenida y favorecida debido a su utilización para techos de casas (más duro que Sabal mauritiiformis).

Varias especies no aparecen como abundantes en las descripciones anteriores (Miranda, 1958). Sin embargo, esto parece deberse a que por ser árboles de tamaño pequeño no son utilizados en la descripción fisonómica de las 
comunidades. Entre ellos se encuentran Ampelocera hottlei, Gymnanthes lucida, Malmea depressa, Neea choriophylla, Pouteria reticulata, Pseudolmedia spuria, Thevetia gaumeri y Trophis racemosa.

Otras dos especies abundantes actualmente son Pouteria amygdalina, restringido al sur de la región y de la que no había registros previos a este trabajo, y Caesalpinia gaumeri, la cual es difícil de distinguir de las otras especies de Caesalpinia y de Haematoxylon. En las selvas inundables, Ateleia gummifera y Malpighia lundellii tampoco son mencionadas por Miranda (1958). Estas especies son difíciles de determinar y posiblemente no fueron identificadas por Miranda.

Especies que han aumentado en menor grado. Varias especies anteriormente registradas como poco abundantes o esporádicas (Miranda, 1958), actualmente son abundantes o muy abundantes. Todas las especies registradas en este grupo son favorecidas por las perturbaciones. Entre éstas se encuentran Brosimum alicastrum, Metopium brownei, Nectandra salicifolia, Pouteria campechiana, Simira salvadorensis y Thouinia paucidentata.

Especies que han disminuido. Varias especies fueron registradas como abundantes (Miranda, 1958) y no se encontraron en nuestros muestreos. Algunas de estas especies han sido fuertemente sobreutilizadas, mientras que otras posiblemente han disminuido debido a sus requerimientos ecológicos. Entre las especies sobreutilizadas están Dendropanax arboreus, de madera blanda de buena calidad, usada para fabricar abatelenguas, lápices y palillos, Bucida buceras, utilizada para durmientes y, por supuesto, Swietenia macrophylla. Chlorophora tinctoria también es fuertemente explotada para la industria de la pintura vegetal (Galletti, 1998; E. Martínez-Salas, obs. pers.).

Entre las especies que han disminuido debido a que necesitan humedad en sus primeras etapas o son sensibles a la perturbación se encuentran Alseis yucatanensis, Maytenus schippi, Protium copal, Sideroxylon salicifolium y Talisia oliviformis (E. Martínez-Salas, obs. pers.). Finalmente, Drypetes lateriflora puede estar ausente de nuestros muestreos por un problema de identificación. Es posible que Miranda (1958) haya considerado a Gymnanthes lucida como Drypetes ya que son árboles muy parecidos cuando no están en floración.

Las diferencias encontradas en la abundancia relativa de las especies en esta comparación sugieren que han ocurrido cambios drásticos en la composición y la estructura de la vegetación en los últimos 45 años. La tendencia general es la disminución de la altura del dosel, el aumento de la abundancia de especies con requerimientos heliófilos favorecidas por perturbaciones y la disminución de especies económicamente importantes y con requerimientos umbrófilos. Además de estos cambios en las especies arbóreas, otros cambios notables son el registro de gran cantidad de especies que se comportan como malezas en el resto del país (Compositae, Graminae; Martínez et al., 1999).

Relevancia de la vegetación (tipos de vegetación únicos). Dentro de las asociaciones descritas destacan cinco por su relevancia regional, nacional y mundial: la selva de guayacán, la selva de jobillo, la selva baja caducifolia, la selva alta y el bajo mixto.

La selva de guayacán de la región de Calakmul representa la única selva de extensión considerable con esta composición florística en Mesoamérica y en el mundo. Guaiacum sanctum es una especie de crecimiento lento y distribución restringida con la mayor parte de su distribución en México. Actualmente se considera con protección especial en la norma 059 (SEMARNAT, 2002). El árbol codominante ("naranjillo") es una especie aún sin describir, que se encuentra hasta el momento restringida a México. En esta asociación se han localizado varias especies de acantáceas endémicas (E. Martínez-Salas, obs. pers.).

La selva de jobillo también destaca debido a que en la región se encuentran poblaciones densas (similares a las del guayacán). Astronium graveolens también se distribuye en las selvas secas del Pacífico y en selvas húmedas de otras partes del país, pero con una abundancia muy baja. Actualmente se encuentra en la categoría de especie amenazada en la Norma Oficial Mexicana 059 (SEMARNAT, 2002). Es una especie poco abundante a nivel nacional con una madera muy atractiva por ser lustrada y brillante.

La selva baja caducifolia ha sido fuertemente modificada en el norte de la península, por lo que la región de Calakmul es de suma importancia. Esta asociación se distribuye en la costa occidental de la República Mexicana hasta el sur del Istmo de Tehuantepec. La distribución de estas selvas está interrumpida por la Selva Lacandona y por la región de los Altos de Chiapas. Al igual que la selva de guayacán, esta comunidad también contiene endemismos muy localizados en un afloramiento yesoso (p. ej. Holographis websteri, Lantana dwyeriana, en la mina de yeso del COCONAL, $1 \mathrm{~km}$ al oeste del ejido Plan de San Luis, 18³2’ N, 89 35' O; Fuirena stephani en la vegetación acuática del rancho Las Delicias, $18^{\circ} 28 \mathrm{~N}, 8^{\circ}{ }^{\circ} 5^{\prime} \mathrm{O}$ (Martínez et al., 2001; E. Martínez-Salas, obs. pers.).

Las selvas altas de la región de Calakmul son las últimas de la península de Yucatán en buen estado de conservación, tanto localmente como regionalmente (más de $5,000 \mathrm{~km}^{2}$ ). Las selvas más húmedas de la ladera oriental han sido fuertemente afectadas debido a los asentamientos humanos. En ellas se han encontrado por lo menos 50\% de los nuevos registros de especies de la zona. Estas selvas representan el límite norte de distribución de este tipo de vegetación en la península de Yucatán.

El bajo mixto es parecido fisonómicamente a los matorrales cercanos al mar en la costa oriental de la península 
(Miranda, 1958). Su distribución está restringida al centro y sur de la península, pero está ausente en el norte. Esta comunidad no se encuentra en ninguna otra región del país. Los bajos mixtos se presentan en suelos con acumulación de yeso, que magnifican la aridez fisiológica en la temporada de secas. Presentan una estructura de selva en miniatura, ya que son muy diversos en elementos dominantes y mantienen también un gran número de especies epífitas (orquídeas y bromeliáceas). Además, contienen una gran variedad de especies de distribución restringida y endémicas en las aguadas asociadas a los bajos con afloramientos de yeso (p.ej. Diospyros bucidaefolia; Martínez et al., 2001).

Importancia ecológica. Se ha sugerido que en las selvas tropicales con alta estacionalidad un número muy bajo de especies de árboles proporcionan el recurso fundamental para mantener a una gran cantidad de especies animales durante la crítica época seca (Terborgh, 1986). En la región de Calakmul varias de las especies dominantes de árboles producen gran cantidad de frutos al final de la época seca (chicle, yaytil, chaka', chechem negro y los naranjillos Esenbeckia spp.) y principios de la época de lluvias (ramón). Además, al parecer existe una complementariedad regional en la producción de frutos entre las selvas de ramón y chicle (parte del año) y las selvas de guayacán y Esenbeckia (todo el año). Esta complementariedad podría explicar los movimientos diarios y estacionales de grandes parvadas de pericos de sus dormideros y sitios de anidación a sus áreas de alimentación (Galindo-Leal, 1999).

El mosaico de diferentes comunidades de vegetación en la región de estudio es de gran importancia para una variedad de especies de animales que obtienen sus recursos en este ambiente heterogéneo, como mariposas y otros invertebrados, anfibios, reptiles, aves y mamíferos. El mosaico sucesional proporciona la heterogeneidad necesaria para los requerimientos de varias especies de aves neotropicales migratorias (Galindo-Leal, 1999).

Comparación de los sistemas de clasificación. La vegetación de la región ha sido caracterizada como selva alta o mediana subperennifolia con zapote, pukté y guano kum (Miranda, 1958), con variantes relacionadas con el cambio de dominancia entre especies como el zapote, el ramón, la guaya, la caoba, el pukte' y el chechem (cuadro 1). Miranda (1958) describió gran parte de la vegetación del centro de la península de Yucatán como selva alta (> de $30 \mathrm{~m}$ de altura) (Miranda, 1958, mapa pag. 223). Sin embargo, en nuestro trabajo encontramos que las selvas altas subperennifolias están restringidas a la parte sur cercana a la frontera con Guatemala y que la mayor extensión está cubierta por selvas medianas. Esta diferencia se debe a la intensa explotación forestal originada a partir de la instalación del segundo torno en el poblado de Zoh-Laguna. De hecho, Miranda (1958) presenta una fotografía de la zona de Zoh-Laguna en donde se puede apreciar una selva alta. Actualmente en esa región se presentan selvas medianas y bajas con dominancia de pocas especies favorecidas por el disturbio. Especies raramente mencionadas por Miranda como Bursera simaruba se han vuelto dominantes.

La presente clasificación sigue un orden jerárquico con tipos de vegetación subdivididos en asociaciones vegetales. Para el nivel de tipos de vegetación se siguieron los criterios ampliamente usados para los tipos de vegetación de México (Miranda y Hernández-X, 1963). La única excepción en este orden jerárquico la presentan los bajos, considerados anteriormente como selva baja espinosa perennifolia (Miranda y Hernández-X, 1963). El segundo nivel representado por las asociaciones vegetales presenta una división más detallada que anteriores clasificaciones, enfatizando la composición de las especies dominantes características.

La identificación de las asociaciones vegetales de esta región mediante la presente clasificación le confiere una gran heterogeneidad que es imposible reconocer con clasificaciones generales que sólo distinguen tipos de vegetación (Flores y Espejel, 1994). A pesar de su escasa heterogeneidad topográfica, la región de Calakmul presenta una gran variedad de comunidades vegetales separadas por distancias relativamente pequeñas. Aunque es considerada como una selva tropical subhúmeda, la carencia estacional de agua, exacerbada por las características físicas y químicas del suelo, determinan que pequeños cambios en el relieve resulten en diferencias relativamente drásticas en la composición florística y la estructura. La consideración de esta heterogeneidad es de suma importancia para entender los procesos ecológicos regionales, así como para las decisiones de conservación y desarrollo.

Conservación. En 1989 se decretó en esta región la Reserva de la Biosfera de Calakmul, que con una extensión de 7,232 $\mathrm{km}^{2}$ constituye el área tropical protegida de mayor tamaño en México. Colindando en el sur se encuentra contigua la Reserva de la Biosfera Maya de Guatemala. En conjunto, ambas reservas cubren una extensión de aproximadamente $17,000 \mathrm{~km}^{2}$, conformando una de las regiones más extensas dedicadas a la conservación (Galindo-Leal, 1999). Esta iniciativa podrá permitir la protección y el reestablecimiento de la vegetación de la región. Sin embargo, a pesar de ser la reserva tropical más grande de México, algunas de las asociaciones vegetales importantes en la región de Calakmul, como la selva de guayacán, están representadas deficientemente, debido a problemas de diseño y del uso de una clasificación generalizada de la vegetación (Galindo-Leal, 1997, 1999; Galindo-Leal et al., 2000). Actualmente, el crecimiento poblacional en la región es muy alto debido tanto a la inmigración como a la tasa de fecundidad (Ericson et al., 1999). El desarrollo turístico relacionado con la Ruta Maya acelera la transformación de la cubierta forestal mediante el 
desarrollo de infraestructura (caminos, aeropuertos, hoteles), incrementando la deforestación a lo largo de carreteras y caminos secundarios (Sandler et al., 1998).

\section{Conclusiones}

A pesar de las fuertes influencias humanas, tanto históricas como recientes, la región de Calakmul contiene una de las extensiones de selvas más amplias y en mejor estado de conservación de la República Mexicana. Además, su localización es estratégica en el esquema de conservación regional, ya que es adyacente a la gran Reserva de la Biosfera Maya en Guatemala y aún mantiene conectividad con la Reserva de la Biosfera de Sian Ka' an en Quintana Roo. Esta conectividad y continuidad le confieren una importancia incluso a nivel mesoamericano.

El estado de conservación actual es el resultado de la inhospitabilidad de la región, debido a la carencia de agua para consumo humano y la escasez de suelo. Estos mismos factores limitantes son los que proporcionan el ambiente heterogéneo, altamente limitante en el cual se han desarrollado la sorprendente variedad de asociaciones vegetales aquí descritas.

\section{Agradecimientos}

Queremos agradecer la cuidadosa revisión de Patricia Balbanera y Carol Boggs al manuscrito. Jorge Meave, Guillermo Ibarra Manríquez y un revisor anónimo proporcionaron innumerables sugerencias que mejoraron el manuscrito. Agradecemos también a las autoridades municipales de Calakmul, a los vigilantes de la caseta de Calakmul y a los custodios del Instituto Nacional de Antropología e Historia (INAH) por las facilidades para llevar a cabo esta investigación. El Herbario de la Universidad Autónoma de Campeche (UCAM) proporcionó bibliografía. Alberto Escamilla y Facundo Contreras de SEMARNAPCampeche ofrecieron apoyo logístico y bibliográfico. Demetrio Alvarez y Santiago Ramírez (ejido Narciso Mendoza) participaron en todos los muestreos y colectas. Muchos viajes y colectas se hicieron con la colaboración ocasional de Pascual y Miguel Alvaro (ejido Dos Lagunas Norte), Gilberto Bacap (Alvaro Obregón), Bennett Sandler (ejido Los Monos Colorados), John Fay, Stuart Weiss, Manuel Weber. Daniel Nogueira (ejido Nueva Vida) además proporcionó alojamiento.

\section{Literatura citada}

Aguilar-Nogales M. 1981. Prospección de minerales no metálicos en el estado de Campeche. Consejo de Recursos Minerales, Gerencia de Exploración Geológica, Quintana Roo. Archivo Técnico, 27 pp.
Andrews G.F. 1996. Arquitecturas Río Bec y Chenes. Arqueología Mexicana 18:16-25.

Carrasco R.V. 1996. Calakmul, Campeche. Arqueología de una "superpotencia". Arqueología Mexicana 18:46-51.

Carrasco R.V. 1997. Consideraciones sobre el Postclásico en la provincia de los Cehaches. En: Calakmul: Volver al Sur, pp. 1322, Ediciones del Gobierno del Estado de Campeche, Campeche.

Comisión Nacional del Agua. 1997. Resumen Anual de Datos Climatológicos. Gerencia Estatal Campeche, Campeche.

Dugelby B. 1998. Governmental and customary arrangements guiding chicle latex extraction in Peten, Guatemala. En: Primack R.B., Bray D., Galletti H.A. y Ponciano I. Eds. Timber, Tourists and Temples, pp. 155-177, Island Press, Washington, D.C.

Ericson J., Freudenberger M.S. y Boege E. 1999. Population Dynamics, Migration, and the Future of the Calakmul Biosphere Reserve. Ocassional Papers of the American Association for the Advancement of Science No. 1. Washington D.C.

Escamilla A., Sanvicente M., Sosa M. y Galindo-Leal C. 2000. Habitat mosaic, wildlife availability and subsistence hunting in the tropical forest of Calakmul, Mexico. Conservation Biology 14:1592-1601.

Flachsenberg H. y Galletti H.A. 1998. Forest management in Quintana Roo, México. En: Primack R.B., Bray D., Galletti H.A. y Ponciano I. Eds. Timber, Tourists and Temples, pp. 47-60, Island Press, Washington, D.C.

Flores J.S. y Espejel I.C. 1994. Tipos de Vegetación de la Península de Yucatán. Etnoflora Yucatanense, Fascículo 3. Universidad Autónoma de Yucatán. Mérida.

Galletti H.A. 1998. The Maya forest of Quintana Roo: thirteen years of conservation and community development. En: Primack R.B., Bray D., Galletti H. y Ponciano I. Eds. Timber, Tourists and Temples, pp. 33-46, Island Press, Washington D.C.

Galindo-Leal C. 1997. Diseño de reservas: el "mal congénito" de Calakmul. Biodiversitas, CONABIO 17:9-15.

Galindo-Leal C. 1999. La gran región de Calakmul, Campeche: prioridades biológicas de conservación y propuesta de modificación de la Reserva de la Biosfera. Reporte a Word Wildlife Fund - México, México D.F. 37 pp.

Galindo-Leal C., Fay J.P. y Weiss S. 2000. Conservation priorities in the greater Calakmul region: correcting the consequences of a congenital illness. Natural Areas Journal 20:376-380.

García G. 1993. Cartografía Temática para el Manejo de la Reserva de la Biosfera de Calakmul, Campeche. Pronatura-Península de Yucatán, Mérida, Yucatán.

García G. 1999. Cartografía Temática para el Manejo de la Reserva de la Biosfera de Calakmul, Campeche. Pronatura-Península de Yucatán, Mérida, Yucatán.

Harrison P.D. 1990. The revolution in ancient maya subsistence. En: Clancy F.S. y Harrison P.D. Eds. Vision and Revision in Maya Studies, pp. 99-124, University of New Mexico Press, Albuquerque, Nuevo México.

Hodell D.A., Curtis J.H. y Brenner M. 1995. Possible role of climate in the collapse of Classic Maya civilization. Nature 375:391394.

Ibarra-Manríquez, G., Villaseñor J.L., Durán R. y Meave J. 2002. Biogeographical análisis of the flora of the Yucatan Peninsula. Journal of Biogeography 29:17-30.

INEGI (Instituto Nacional de Geografía y Estadística). 1996. Anuario Estadístico del Estado de Campeche. INEGI, Gobierno del Estado de Campeche, Aguascalientes, Aguascalientes. 
Lundell C.L. 1933. Chicle explotation in the sapodilla forest of the Yucatán Península. Field and Labor 2:15-21.

Lundell C.L. 1934. Preliminary sketch of the phytogeography of the Yucatán Peninsula. Carnegie Institute of Washington Publications 436:257-321.

Lundell C.L. 1937. The Vegetation of Petén. Carnegie Institute of Washington, Publication 478. Washington, D.C.

Martínez E., Sousa M.S. y Ramos Álvarez C.H. 2001. Flora de Calakmul. Listados Florísticos de México. Instituto de Biología, Universidad Nacional Autónoma de México, México, D.F.

Martínez E., Toledo V.M. y Ramos C.H. 2000. La vegetación de las cañadas. Chapingo, Serie Ciencias Forestales y del Ambiente 5:15-26.

Miranda F. 1951. La vegetación de Chiapas. Vol. 1. Gobierno del Estado de Chiapas, Tuxtla Gutiérrez, Chiapas.

Miranda F. 1958. Rasgos fisiográficos de interés para los estudios biológicos. En: Beltrán E. Ed. Los Recursos Naturales del Sureste y su Aprovechamiento, pp. 161-173, Tomo II. Instituto Mexicano de Recursos Naturales Renovables, México., D.F.

Miranda F. y Hernández-X E. 1963. Tipos de vegetación de México y su clasificación. Boletín de la Sociedad Botánica de México 28:29-179.

Pennington T.D. 1990. Sapotaceae. Flora Neotropica Monographs 52:1-771.

Pennington T.D. y Sarukhán J. 1998. Árboles Tropicales de México. Universidad Nacional Autónoma de México y Fondo de Cultura Económica, México. D.F.

Pérez L.A., y Sarukhán J. 1970. La vegetación de la región de Pichucalco, Chiapas. Publicaciones Especiales del Instituto Nacional de Investigaciones Forestales 5:49-123.

Pino E. 1997. Calakmul: una deuda histórica comienza a saldarse. En: Calakmul: volver al Sur, pp. 193-216, Gobierno del Estado, Campeche.

Pohl M. (ed.). 1985. Prehistoric Lowland Maya Environment and Subsistence Economy. Papers of the Peabody Museum of Archaeology and Ethnology. Vol. 77. Harvard University, Cambridge, Massachusetts.

Ponce M.P. 1990. La Montaña Chiclera. Campeche: Vida Cotidiana y Trabajo (1900 - 1950). Cuadernos de la Casa Chata 172. Secretaría de Educación Pública, México, D.F.

Rzedowski J. 1978. Vegetación de México. Ed. Limusa. México, D.F.

Revel-Mouroz J. 1972. Aprovechamiento y Colonización del Trópico Húmedo Mexicano. Fondo de Cultura Económica, México, D.F.

Rico-Gray V., García-Franco J.G., Puch A. y Sima P. 1988. Composition and structure of a tropical dry forest in Yucatán, México. International Journal of Ecology and Environmental Science 14:21-29.

Sandler B., Weiss S., Fay J., Martínez E. y Galindo-Leal C. 1998. Análisis de la deforestación y de los tipos de vegetación de la Reserva de la Biosfera de Calakmul, utilizando sensores remotos. Reporte Final Inédito. World Wildlife Fund-México, México D.F. 38 pp.

Schulze M. y Whitacre D. 1999. A classification and ordination of the tree community of Tikal National Park, Peten, Guatemala. Bulletin of the Florida Museum of Natural History 41:169-297.

SEMARNAT (Secretaría de Medio Ambiente y Recursos Naturales). 2002. Norma Oficial Mexicana NOM-059-ECOL-2001, Protección ambiental - Especies nativas de México de flora y fauna silvestres - Categorías de riesgo y especificaciones para su inclusión, exclusión o cambio -Lista de especies en riesgo. Diario Oficial de la Federación, 6 de marzo de 2002, 1-56.

Snook L.K. 1998. Sustaining harvests of mahogany (Swietenia macrophylla King) from Mexico's Yucatán Forests: past, present and future. En: Primack R.B., Bray D., Galletti H.A. y Ponciano I. Eds. Timber, Tourists and Temples, pp. 61-80, Island Press, Washington, D.C.

Sosa V., Flores J.S., Rico-Gray V., Lira R. y Ortiz J.J. 1985. Lista Florística y Sinonimia Maya. Etnoflora Yucatanense, Fascículo 1. Instituto Nacional de Investigaciones sobre Recursos Bióticos, Mérida.

Standley P.C. 1930. Flora of Yucatan. Publications - Field Museum of Natural History, Botanical Series 3:157-429.

Terborgh J. 1986. Keystone plant resources in tropical forest. En: Soulé M.E. Ed. Conservation Biology: the Science of Scarcity and Diversity, pp. 330-334, Sinauer Associates, Sunderland, Massachusetts.

Thien L.B., Bradburn A.S., y Welden A.L. 1982. The Woody Vegetation of Dzibilchaltun, a Mayan Archaeological Site in Northwest Yucatan, Mexico. Middle American Research Institute, Occasional Papers No. 5, Nueva Orleans, Lousiana.

Turner B.L. II. 1983. Once Beneath the Forest. Prehistoric Terracing in the Río Bec Region of the Maya Lowlands. Dellplain Latin American Studies, No. 13, Westview Press, Boulder, Colorado.

Turner B.L. y Powell A.M. 1979. Deserts, gypsum and endemism. En: Goodin J.R. y Northington D.K. Eds. Arid Land Plant Resources, pp. 96-116, International Center for Arid and Semi-Arid Land Studies, Texas Technical University, Lubbock, Texas.

Villaseñor R. 1958. Los bosques y su explotación. En: Beltrán E. Ed. Los Recursos Naturales del Sureste y su Aprovechamiento, pp. 275-326, Instituto Mexicano de Recursos Naturales Renovables, México, D.F.

Wendt T. 1989. Las selvas de Uxpanapa, Veracruz-Oaxaca, México: evidencia de refugios florísticos cenozoicos. Anales del Instituto de Biología, Universidad Nacional Autónoma de México, Serie Botánica 58:29-54.

Wendt T. 1993. Composition, floristic affinities, and origins of the canopy tree flora of the Mexican Atlantic slope rain forest. En: Ramamoorthy T.P.R., Bye R., Lot A. y Fa J. (eds.) Biological Diversity of Mexico: Origins and Distribution, pp. 595-680, Oxford University Press, Nueva York.

Whigham D.F., Zugasty-Towle P., Cabrera-Cano E., Nelly J.O. y Ley E. 1990. The effect of annual variation in precipitation on growth and litter production in a tropical dry forest in the Yucatan of Mexico. Tropical Ecology 31:23-24.

Whigham D.F., Olmsted I., Cano E.C. y Harman M.E. 1991. The impact of hurricane Gilbert on trees, litterfall, and woody debris in a dry tropical forest in the northeastern Yucatan Peninsula. Biotropica 23:434-441.

White D.A. y Darwin S.P. 1995. Woody vegetation of tropical lowland deciduous forests and Mayan ruins in the north-central Yucatan peninsula, Mexico. Tulane Studies in Zoology and Botany 30:1-25. 
Apéndice 1. Nombres científicos y comunes de las especies mencionadas en el texto y de algunas otras de las que se conoce el nombre común.

\section{Nombre científico}

Acacia cornigera (L.) Willd.

Acacia dolichostachya S.F.Blake

Acacia gaumeri S.F.Blake

Acoelorraphe wrightii (Griseb. et H.Wendl.) H. Wendl. ex Becc.

Acrocomia mexicana Karw. ex Mart.

Agonandra aff. ovatifolia Miranda

Alseis yucatanensis Standl.

Ampelocera hottlei (Standl.) Standl.

Amyris elemifera $\mathrm{L}$.

Amyris sylvatica Jacq.

Annona primigenia Standl. et Steyerm.

Aspidosperma cruentum Woodson

Aspidosperma megalocarpon Müll.Arg.

Astronium graveolens Jacq.

Ateleia gummifera (Bertero ex DC.) D.D ietr.

Beaucarnea pliabilis (Baker) Rose

Bravaisia berlandieriana ( $\mathrm{N}$ ees) T.F.D aniel

Brosimum alicastrum Sw.

Bucida buceras L.

Bursera simaruba (L.) Sarg.

Byrsonima bucidaefolia Standl.

Byrsonima crassifolia (L.) Kunth

Caesalpinia gaumeri Greenm.

Caesalpinia mollis (Kunth) Spreng.

Caesalpinia vesicaria $\mathrm{L}$.

Calathea lutea (Aubl.) Schult.

Calophyllum brasiliense Cambess.

Cameraria latifolia L.

Canella winteriana (L.) Gaertn.

Casearia arborea (Rich.) U rb.

Casearia emarginata C.W right ex G riseb.

Casimiroa tetrameria Millsp.

Cecropia peltata L.

Cedrela odorata L.

Ceiba pentandra (L.) Gaertn.

Ceiba schotti Britten et Baker $f$.

Chlorophora tinctoria (L.) Gaudich. ex Benth.

Chrysobalanus icaco L.

Chrysophyllum venezuelanense (Pierre) T.D.Penn.

Chusquea sp.

Cladium jamaicense Crant

Clusia flava Jacq.

Coccoloba acapulcensis Standl.

Coccoloba aff. belizensis Standl.

Coccoloba cozumelensis Hemsl.

Coccoloba reflexiflora Standl.

Coccoloba schiedeana Lindau

Cochlospermum vitifolium (W illd.) Spreng.

Colubrina greggii S.W atson

Cordia dodecandra A.DC.

Coussapoa purpusii Standl.

Crescentia cujete L.

Croton icche Lundell

\section{Nombre común}

subín

kabal piich

box kaatsim

palma tasiste'

palma de coyol; tuk

xnauche

palo de gas

palo de gas

anonilla; anona de monte

bayo rojo; peel ma'ax

bayo blanco; peel ma'ax

jobillo; k'ulim che'

despeinada; ts'ipil

julubal

ramón

pukte'

chaká

nance agrio; sak paj

nance

tinto puerco; kitamche'

chakte'viga

chiin tok

hoja blanca

barí

chechén blanco; sac cheechem

ixilim che'

iik'il che'

matabejas; jyuuy

guarumbo

cedro

piim; ceiba

rabo de lagarto

icaco

carrizo

jol che'

chunuup

boochi che'

boochi che'

boochi che'

boochi che'

boochi che'

chak ch'ooy

box ooxh

siricote; k'oopte

amate

güiro; joma'

p'ere'es k'uuch 


\section{Nombre científico}

Croton lundellii Standl.

Cryosophila argentea Bartlett

Cupania belizensis Standl.

Cymbopetalum mayanum Lundell

Cyperus articulatus $\mathrm{L}$.

Dendropanax arboreus (L.) Decne. et Planch.

Diospyros bucidaefolia Standl.

Diospyros bumelioides Standl.

Diospyros salicifolia Humb. \& Bonpl. ex Willd.

Diospyros yatesiana Standl.

Enterolobium cyclocarpum (Jacq.) Griseb.

Ehretia tinifolia L.

Erythroxylum obovatum Macfad.

Erythroxylum rotundifolium Lunan

Esenbeckia sp. nov.

Eugenia capuli (Schltdl. et Cham.) O .Berg

Eugenia ibarrae Lundell

Eugenia winzerlingii Standl.

Eugenia aff. winzerlingii Standl.

Exostema mexicanum A.G ray

Exothea diphylla (Standl.) Lundell

Ficus cf. turrialbana W.C.Burger

Ficus obtusifolia Kunth

Fuirena stephani Ramos et N.Diego

Gaussia maya (O .F.Cook) H.J.Q uero R. et R.W.Read

Gliricidia maculata (Kunth) Walp.

Guaiacum sanctum L.

Guettarda combsii U rb.

Gymnanthes lucida Sw.

Gymnopodium floribundum Rolfe

Haematoxylum brasiletto H.Karst.

Haematoxylum campechianum L.

Hampea trilobata Standl.

Havardia albicans (Kunth) Britton et Rose

Hemiangium excelsum (Kunth) A.C.Sm.

Hirtella americana L.

Holographis websteri T.F.Daniel

Hyperbaena winzerlingii Standl.

Jacquinia flammea Millsp. ex M ez

Jacquinia macrocarpa Cav.

Jatropha gaumeri Greenm.

Karwinskia humboldtiana (Willd. ex Roem. \& Schult.) Zucc.

Krugiodendron ferreum (Vahl) U rb.

Laetia thamnia L.

Lantana dwyeriana M oldenke

Licaria coriacea (Lundell) Kosterm.

Licaria campechiana (Standl.) Kosterm.

Lonchocarpus castilloi Standl.

Lonchocarpus hondurensis Benth.

Lonchocarpus rugosus Benth.

Lonchocarpus xuul Lundell

Lonchocarpus yucatanensis Pittier

Luehea speciosa Willd.

Lysiloma latisiliqua A. G ray ex Sauvalle

Machaonia lindeniana Baill.

Malmea depressa (Baill.) R.E.Fr.

\section{Nombre común}

achiotillo

guano kum

sak poom

orejuela; guineillo

xtupux xu'uk

siliil

siliil

box siliil

pich

bek; roble

iik'il che'

iik'il che'

naranjillo; jo'ok'ob

guayabillo

guayabillo

ich juuj

ich juuj

quina

wayam cox

amate

amate; koopo'

kabal xa'an

palma

k'uchunuk; cocoite

guayacán; guayacán negro; chuum chiin took'

tas ta'ab; pay luuk'

yaytil

sak ts'iits'il che'

tinto de montaña

tinto

majagua; jool

chimay

chum loob

tripa de cochino; choch kitan

chak si'ik'in k'aax

chak si'ik

piñón; chul che'

lu'um chakte'

chintok

ximche'

machiche

ya'ax ja'abin

$k^{\prime}$ anatsin

$x u$ 'ul

$x u$ 'ul de montaña

patastillo; chakats

tsalam

box k'u'ch'eel

e'ele'muy; yaya 


\section{Nombre científico}

Malpighia Iundellii C.V.M orton

Manilkara chicle (Pittier) Gilly

Manilkara zapota (L.) P. Royen

Maytenus schipii Lundell

Metopium brownei (Jacq.) U rb.

Mimosa bahamensis Benth.

Mimosa pigra L.

Myroxylum balsamum (L.) H arms

Myrcianthes fragrans (Sw.) M cVaugh

Nectandra coriacea (Sw.) G riseb.

Nectandra salicifolia (Kunth) $\mathrm{N}$ ees

Neea choriophylla Standl.

$N$ eea psychotrioides Donn.Sm.

N eomillspaughia emarginata (H. Gross) S.F. Blake

O rbignya cohune (M art.) D ahlgren ex Standl.

Pilocarpus racemosus Vahl

Pimenta dioica (L.) Merr.

Piscidia piscipula (L.) Sarg.

Platymiscium yucatanum Standl.

Plumeria obtusa L.

Pouteria amygdalina (Standl.) Baehni

Pouteria campechiana (Kunth) Baehni

Pouteria durlandii (Standl.) Baehni

Pouteria reticulata (Engl.) Eyma

Pouteria sapota (Jacq.) H.E.M oore et Stearn

Protium copal (Schltdl.et Cham.) Engl.

Pseudobombax ellipticum (Kunth) Dugand

Pseudolmedia spuria (Sw.) G riseb.

Pteridium aquilinum (L.) Kuhn

Randia aculeata L.

Sabal mauritiiformis (H.Karst.) Griseb. et H.W endl.

Sabal yapa C.W right ex Becc.

Sebastiania adenophora Pax et K.H offm.

Simarouba glauca DC.

Simira salvadorensis (Standl.) Steyerm.

Spondias mombin L.

Swartzia cubensis (Britton et P.Wilson) Standl.

Swietenia macrophylla King

Sideroxylon floribundum Griseb.

Sideroxylon foetidissimum Jacq.

Sideroxylon salicifolium (L.) Lam.

Tabebuia chrysantha (Jacq.) G.N icholson

Tabebuia rosea (Bertol.) A.DC.

Talisia floresii Standl.

Talisia oliviformis (Kunth) Radlk.

Terminalia amazonia (J.F.Gmel.) Exell

Thalia geniculata $\mathrm{L}$.

Thevetia gaumeri $\mathrm{Hemsl}$.

Thouinia paucidentata Radlk.

Typha domingensis Pers.

Trophis racemosa (L.) U rb.

Viguiera dentata (Cav.) Spreng.

Vitex gaumeri Greenm.

Zuelania guidonia (Sw.) Britton et Millsp.

\section{Nombre común}

wayakte'

oreja de burro; chicle de segunda

chicle; sapote

chechem negro; box cheechem

sac kaatsim

kuka

nabal; bálsamo

xokoka'an

laurelillo

siipche'

chak much

saj iitsa'

palma corozo

naranjillo

pimienta

ja'abin

granadillo; subin che'

flor de mayo; nikte'ch'oom

sapote faisán

kaniste'

sapotillo

sapotillo

sapote mamey

copal

amapola

mamba

crespillal

peech kitam

guano

guano yucateco

chechem blanco

pasa

palo de rosa; chaka'huanté

jobo; abal

katalox

caoba

tempesquite; capir

tempesquite; capir

tsiitsil yaj; sapotillo

guayacán amarillo; ajaw che'

makulis

kolok

guaya

k'anxa'an

popal

campanilla; aki'its

hueso de tigre; $k^{\prime}$ anchunup

x-pujil

ramón colorado

tajonal

ya'axnik

trementino; tamay 